\title{
Biotic Supplements for Renal Patients: A Systematic Review and Meta-Analysis
}

\author{
Anna Pisano ${ }^{1}$, Graziella D'Arrigo ${ }^{1}$, Giuseppe Coppolino ${ }^{2}$ (D) and Davide Bolignano ${ }^{1, *(1)}$ \\ 1 CNR-Institute of Clinical Physiology, Reggio Calabria 89124, Italy; pisanoanna@hotmail.it (A.P.); \\ g.darrigostat@tin.it (G.D.) \\ 2 Nephrology and Dialysis Unit, "Pugliese-Ciaccio" Hospital of Catanzaro, Catanzaro 88100, Italy; \\ gcoppolino@hotmail.it \\ * Correspondence: davide.bolignano@gmail.com; Tel.: +39-0965-3932-52
}

Received: 15 June 2018; Accepted: 29 August 2018; Published: 4 September 2018

\begin{abstract}
Intestinal dysbiosis is highly pervasive among chronic kidney disease (CKD) patients and may play a key role in disease progression and complications. We performed a systematic review and meta-analysis to evaluate effects of biotic supplements on a large series of outcomes in renal patients. Ovid-MEDLINE, PubMed and CENTRAL databases were searched for randomized controlled trials (RCTs) comparing any biotic (pre-, pro- or synbiotics) to standard therapy or placebo. Primary endpoints were change in renal function and cardiovascular events; secondary endpoints were change in proteinuria/albuminuria, inflammation, uremic toxins, quality of life and nutritional status. Seventeen eligible studies (701 participants) were reviewed. Biotics treatment did not modify estimated glomerular filtration rate (eGFR) (mean difference (MD) $0.34 \mathrm{~mL} / \mathrm{min} / 1.73 \mathrm{~m}^{2} ; 95 \% \mathrm{CI}$ $-0.19,0.86$ ), serum creatinine (MD $-0.13 \mathrm{mg} / \mathrm{dL} ; 95 \%$ confidence interval (CI) $-0.32,0.07$ ), C-reactive protein (MD $0.75 \mathrm{mg} / \mathrm{dL} ; 95 \% \mathrm{CI}-1.54,3.03$ ) and urea (standardized MD (SMD) $-0.02 ; 95 \% \mathrm{CI}-0.25$, 0.20 ) as compared to control. Outcome data on the other endpoints of interest were lacking, sparse or in an unsuitable format to be analyzed collectively. According to the currently available evidence, there is no conclusive rationale for recommending biotic supplements for improving outcomes in renal patients. Large-scale, well-designed and adequately powered studies focusing on hard rather than surrogate outcomes are still awaited.
\end{abstract}

Keywords: chronic kidney disease; end-stage kidney disease; gut microbiota; prebiotics; probiotics; synbiotics

\section{Introduction}

Under healthy conditions, the gut hosts more than 100 trillion microbial cells that play an active role in regulating physiology, metabolism, nutrition and even the immune function of the human body. This results from a subtle symbiotic relationship between microbiome and host, in which an imbalance may trigger or exacerbate several pathological conditions not limited to the intestinal tract, such as obesity, insulin resistance, cancer, diabetes and chronic inflammatory systemic diseases [1]. There is now accruing evidence indicating that chronic kidney disease (CKD), particularly end-stage kidney disease (ESKD), causes dysbiosis of the intestinal microbiome by increasing the presence of pathogenic flora over symbiotic bacteria. Gut pathogens enhance protein fermentation, eventually generating waste metabolites such as indoles, phenols and amines; in addition, endotoxins produced by these harmful microbes may elicit a local inflammatory response which alters the permeability of the intestinal barrier, leading to an increased absorption of toxic substances into the systemic circulation. In renal patients, such mechanisms have been called into question as key 
triggers towards systemic inflammation, malnutrition, uremic toxicity and even progression of CKD and associated cardiovascular (CV) disease [2].

Targeted interventions to restore symbiosis have hence been proposed and tested in this population setting for alleviating uremic symptoms and improve renal outcomes. These may include the administration of 1) prebiotics, which are non-digestible fiber compounds stimulating the growth or activity of advantageous bacteria; 2) probiotics, which are, on the contrary, live beneficial microorganisms commonly employed to improve digestive health; 3 ) synbiotics, which represent a synergistic combination of pre- and pro-biotics.

The mechanism by which these products exert their favorable effects may include protection of the intestinal barrier, changes in intestinal $\mathrm{pH}$ and suppression of pathogens by competitive exclusion and competition for available nutrients [3].

However, despite a wealth of animal studies and small uncontrolled pilot trials that evidenced a positive impact of biotic supplements towards the clinical course of CKD [4], no univocal benefits were reported by more recent randomized clinical trials focusing on a myriad of endpoints pertaining to renal function/damage, uremic toxicity or inflammation [5-7].

With this background in mind, we therefore felt it necessary to perform a systematic review focusing on randomized clinical evidence in order to ascertain whether chronic biotic supplementation should indeed be advocated as an additive therapeutic measure for improving outcomes of renal patients.

\section{Methods}

This review follows PRISMA guidelines [8] for reporting in systematic reviews and meta-analysis and was conducted according to a previously published protocol (PROSPERO ID: CRD42018087391).

\subsection{Data Source and Search Strategy}

Ovid-MEDLINE, PubMed and CENTRAL databases were searched for articles without time or language restriction up to 5 March 2018 using focused, highly sensitive search strategies (Supplementary Table S1). References from relevant studies and reviews were screened for additional articles. The search was designed and performed by three authors (D.B., A.P., G.C.).

\subsection{Study Selection and Data Extraction}

We aimed at including any randomized control trials (RCT) or quasi-RCT (trials in which allocation to treatment was made by alternation, use of alternate medical records, date of birth or other expected methods) testing the effects of biotic supplements (pre-, pro- or synbiotics) in patients with chronic kidney disease (CKD) or end-stage kidney disease (ESKD) on chronic renal replacement therapy by hemodialysis, peritoneal dialysis or kidney transplantation.

Studies were considered regardless of dosage of supplementation and without language and follow-up duration restrictions. Any type of comparator was contemplated, including but not limited to placebo and standard treatment. Studies comparing the same intervention employed at different doses were excluded.

The presence of CKD was defined according to the National Kidney Foundation Kidney Disease Outcomes Quality Initiative (NKF KDOQI) guidelines [9] by a reduced glomerular filtration rate (GFR) $<90 \mathrm{~mL} / \mathrm{min} / 1.73 \mathrm{~m}^{2}$ or by the persistence of urinary abnormalities, (albuminuria, proteinuria or hematuria) in subjects with GFR $\geq 90 \mathrm{~mL} / \mathrm{min} / 1.73 \mathrm{~m}^{2}$.

The primary endpoint of interest was CKD progression, either defined as a stable increase in serum creatinine or estimated GFR (eGFR)/creatinine clearance decrease; CV mortality and morbidity (non-fatal CV events).

Secondary outcomes were change in proteinuria and albuminuria, inflammation indexes, azotemia and other uremic toxins (including but not limited to p-cresol and indoxyl sulfate), quality of life and nutritional status. 
Studies were excluded if: 1) dealing with CKD patients on acute renal replacement therapy (e.g., acute hemo- or peritoneal dialysis), 2) employing biotic supplements for other clinical indications (e.g., digestive diseases, intestinal autoimmune or infectious diseases), 3) employing an undefined combination of dietary fibers with unproven pre-biotic effects 4) not providing data on the outcomes of interest.

Studies where at least part of the population fulfilled the above criteria were included in the review.

Titles and abstracts were screened independently by two authors (A.P., G.D.), who discarded studies not pertinent to the topic. Non-randomized trials, case reports, case series, reviews, editorials, letters and studies performed on children (age <18) were excluded from qualitative analyses but screened for potential additional references. Two authors (A.P., G.D.) independently assessed the retrieved abstracts and the full text of these studies to determine eligibility according to the inclusion/exclusion criteria.

A third reviewer (D.B.) solved possible discrepancies on study judgments. Data extraction and analysis were performed by two reviewers (A.P., G.D.) and independently verified by another (G.C.).

\subsection{Data Analysis}

Cumulative meta-analyses were performed for outcomes reported, in a suitable and consistent format, by more than two studies. In order to maximize the information provided to readers, data on outcomes stated by single studies or in a descriptive way were reported narratively. The effects of treatment on continuous variables were assessed as mean difference (MD) or standardized mean difference (SMD), as appropriate. Data were pooled using the random-effects model. To ensure robustness of the model and susceptibility to outliers, pooled data were also analyzed with the fixed-effects model. Heterogeneity was assessed by the Chi-squared test on N-1 degrees of freedom, with an alpha of 0.05 considered for statistical significance and the Cochrane-I-squared $\left(I^{2}\right)$ statistic. $I^{2}$ values of $25 \%, 50 \%$ and $75 \%$ were considered to correspond to low, medium and high levels of heterogeneity, respectively. Sources of heterogeneity, for identifying possible effect modifiers on the pooled analyses, were explored by sensitivity analyses according to: population characteristics, type and dose of biotic administered, study design or follow-up duration where feasible according to the number of studies matching the same characteristic.

Publication bias was investigated by the Egger's regression test and by visual inspection of funnel plots. Statistical analyses were performed by two authors (A.P., G.D.) using Review Manager (RevMan; Version 5.3. Copenhagen: The Nordic Cochrane Centre, The Cochrane Collaboration, 2014) and Stata/IC (Version 13.1, StataCorp LP, Texas, USA).

\subsection{Risk of Bias Assessment}

Likelihood of bias in the single RCTs was evaluated by using the checklist developed by the Cochrane Renal Group which considers the presence of potential selection bias (random sequence generation and allocation concealment), performance bias (blinding of investigators and participants), detection bias (blinding of outcome assessors), attrition bias (incomplete outcome data), reporting bias (selective reporting) and possible other sources of bias (e.g., funding bias).

\section{Results}

\subsection{Search Results}

Figure 1 shows the flow diagram of the study selection process. Three hundred and twenty potentially relevant references were initially found. Five additional citations were added by personal search. By screening titles and abstracts, 295 citations were excluded for various reasons (search overlap, study population or intervention or outcome not pertinent, no RCTs, review articles or other topic). 
Amongst the 30 articles selected for full text examination, nine studies were excluded because: 1$)$ no RCT $(n=3), 2)$ dealing with the wrong population $(n=4), 3)$ not providing data on the outcomes of interest $(n=2)$.

A total of 21 articles referring to 17 studies (701 participants) were finally reviewed.

Twelve randomized trials (530 participants) providing suitable numerical data on the outcomes of interest were included in the cumulative meta-analyses. The main characteristics of these studies are summarized in Table 1.

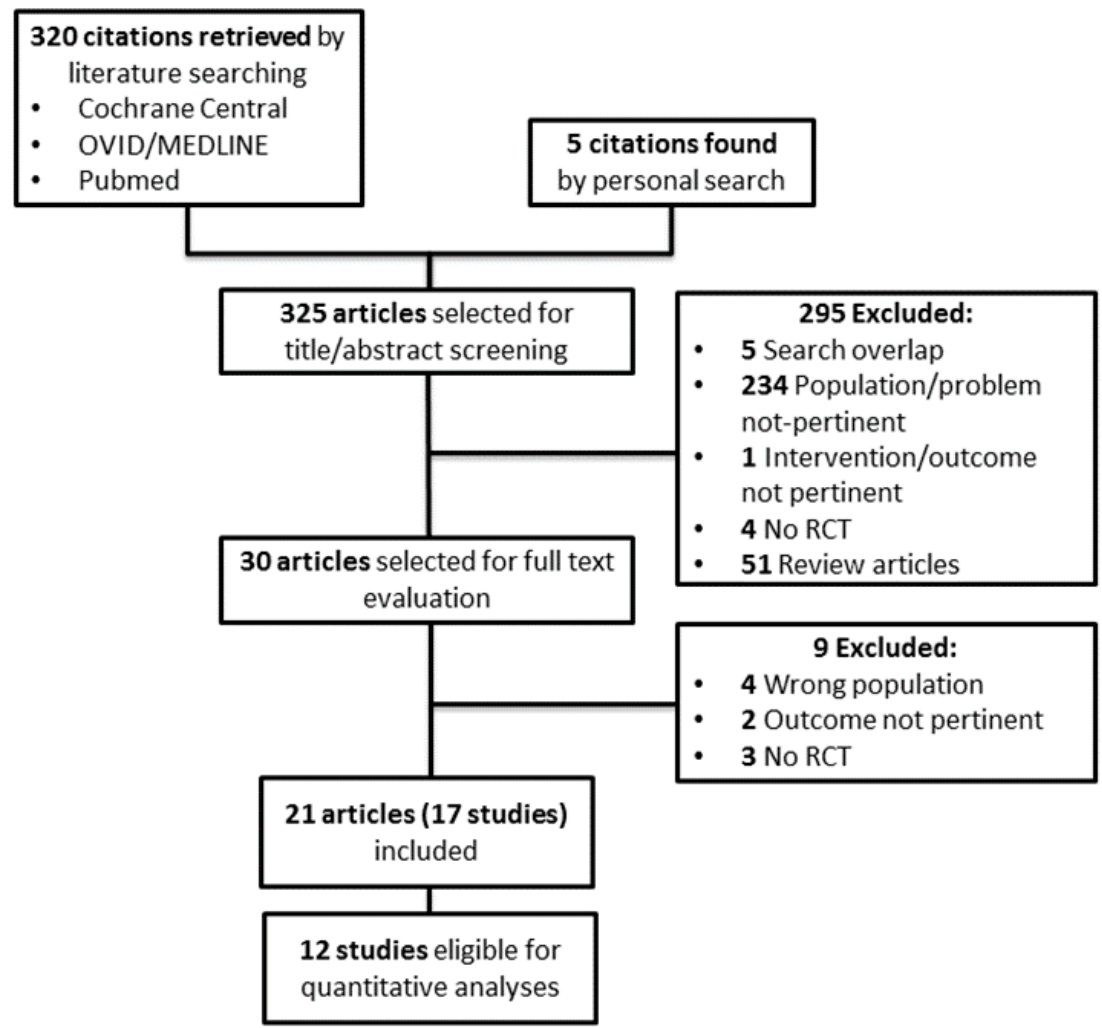

Figure 1. Study selection flow. RCT = randomized control trial. 
Table 1. Summary of main characteristics and findings of the RCTs reviewed.

\begin{tabular}{|c|c|c|c|c|c|c|c|c|}
\hline Study, Year (ref.) & $\begin{array}{l}\text { Inclusion Criteria } \\
\text { Exclusion Criteria }\end{array}$ & $\begin{array}{c}\text { Population } \\
\text { Characteristics }\end{array}$ & Intervention & Control & Duration & Outcome(s) & Results & Notes \\
\hline \multirow{3}{*}{ Bliss et al., 1996 [10] } & \multirow{3}{*}{$\begin{array}{c}\text { months } \\
\text { Liver diseases, HD, renal } \\
\text { transplantation, active } \\
\text { gastrointestinal bleeding, } \\
\text { pregnancy or lactating }\end{array}$} & \multirow{3}{*}{$\begin{array}{c}n=16 \\
\text { Men }(\%)=63 \\
\text { Urea }(\mathrm{mg} / \mathrm{dL})= \\
50 \pm 6 \\
\mathrm{SCr}(\mathrm{mg} / \mathrm{dL})= \\
4.4 \pm 0.8\end{array}$} & \multirow{3}{*}{$\begin{array}{l}\text { Prebiotics } \\
\text { (Gum arabic } \\
\text { fiber, } 25 \mathrm{~g} \\
\text { twice/daily) } \\
\quad(n=16)\end{array}$} & \multirow{3}{*}{$\begin{array}{l}\text { Placebo } \\
(n=16)\end{array}$} & \multirow{3}{*}{$\begin{array}{l}\text { Eight } \\
\text { weeks }\end{array}$} & $\mathrm{SCr}(\mathrm{mg} / \mathrm{dL})$ & $\begin{array}{l}\text { End of treatment, } 4.5 \pm 3.2 \text { vs. } 4.7 \pm 3.6 \text { in } \\
\text { prebiotic vs. placebo group }(p=0.12)\end{array}$ & \multirow{3}{*}{$\begin{array}{l}\text { Single blind, cross-over } \\
\text { Four drop-outs; per-protocol } \\
\text { analysis performed }\end{array}$} \\
\hline & & & & & & & & \\
\hline & & & & & & Urea $(\mathrm{mg} / \mathrm{dL})$ & $\begin{array}{l}\text { End of treatment, } 44 \pm 20 \text { vs. } 52 \pm 32 \text { in } \\
\text { prebiotic vs. placebo group }(p<0.05)\end{array}$ & \\
\hline \multirow{3}{*}{$\begin{array}{l}\text { Younes et al., } \\
2006[11]\end{array}$} & \multirow{3}{*}{$\begin{array}{l}\text { CKD patients underwent } \\
\text { a restrictive protein diet } \\
(0.8 \mathrm{~g} / \mathrm{kg} / \text { day })\end{array}$} & \multirow{3}{*}{$\begin{array}{c}n=9 \\
\text { Age }(\text { year })= \\
67.7 \pm 11.5 \\
\text { Men }(\%)=33 \\
\text { Urea }(\mathrm{mmol} / \mathrm{L})= \\
25 \pm 5 \\
\mathrm{CrCl}(\mathrm{mL} / \mathrm{min})= \\
25 \pm 5\end{array}$} & \multirow{3}{*}{$\begin{array}{c}\text { Prebiotics } \\
\text { (Fermentable } \\
\text { carbohydrate } \\
40 \mathrm{~g} / \text { day) } \\
(n=9)\end{array}$} & \multirow{3}{*}{$\begin{array}{l}\text { Standard } \\
\text { treatment } \\
(n=9)\end{array}$} & \multirow{3}{*}{10 weeks } & $\mathrm{CrCl}(\mathrm{mL} / \mathrm{min})$ & $\begin{array}{l}\text { End of treatment, } 24.2 \pm 13.9 \text { vs. } 22.6 \pm 12.2 \\
\text { in prebiotic vs. control group }(p>0.05)\end{array}$ & \multirow{3}{*}{$\begin{array}{c}\text { Open label, cross-over } \\
\text { Prebiotic supplementation } \\
\text { consisted of } 25 \mathrm{~g} \text { of whole-meal } \\
\text { bread, } 4.5 \mathrm{~g} \text { inulin and } 10.5 \mathrm{~g} \\
\text { crude potato starch }\end{array}$} \\
\hline & & & & & & $\mathrm{SCr}(\mu \mathrm{mol} / \mathrm{L})$ & $\begin{array}{l}\text { End of treatment, } 339 \pm 146 \text { vs. } 357 \pm 143 \text { in } \\
\text { prebiotic vs. control group }(p>0.05)\end{array}$ & \\
\hline & & & & & & Urea $(\mathrm{mmol} / \mathrm{L})$ & $\begin{array}{l}\text { End of treatment, } 20.2 \pm 8.2 \text { vs. } 26.1 \pm 8.7 \text { in } \\
\text { prebiotic vs. control group }(p<0.05)\end{array}$ & \\
\hline \multirow{4}{*}{$\begin{array}{l}\text { Ranganathan et al., } \\
2010^{*}[12] \\
\text { Ranganathan et al., } \\
2009\end{array}$} & \multirow{4}{*}{$\begin{array}{l}\text { Stage 3-4 CKD patients } \\
\text { Antibiotic treatment } \\
\text { within } 14 \text { days before } \\
\text { screening, drugs or } \\
\text { alcohol dependence, HIV, } \\
\text { liver disease, any medical, } \\
\text { psychiatric, debilitating } \\
\text { disease, anticoagulant } \\
\text { therapy, pregnancy }\end{array}$} & \multirow{4}{*}{$\begin{array}{c}n=46 \\
\text { Age }(\text { year })=\sim 56 \\
\text { Men }(\%)=67 \\
\text { DM }(\%)=41\end{array}$} & \multirow{4}{*}{$\begin{array}{c}\text { Probiotics } \\
\text { (two capsules } \\
\text { thrice/daily) } \\
(n=46)\end{array}$} & \multirow{4}{*}{$\begin{array}{l}\text { Placebo } \\
(n=46)\end{array}$} & \multirow{4}{*}{$\begin{array}{c}\text { Six } \\
\text { months }\end{array}$} & $\mathrm{SCr}(\mu \mathrm{mol} / \mathrm{L})$ & $\begin{array}{l}\text { End of treatment, } 388.52 \pm 229.85 \text { vs. } \\
414.04 \pm 342.34 \text { in probiotic vs. placebo } \\
\text { group }(p=0.23)\end{array}$ & \multirow{4}{*}{$\begin{array}{l}\text { Double blind, cross-over } \\
\text { Each capsule (15 billion CFU) } \\
\text { of probiotic supplementation } \\
\text { contained L. acidophilus, B. } \\
\text { longum and S. thermophilus } \\
\text { Sixteen drop-outs; per-protocol } \\
\quad \text { analysis performed }\end{array}$} \\
\hline & & & & & & $\mathrm{BUN}(\mu \mathrm{mol} / \mathrm{L})$ & $\begin{array}{l}\text { End of treatment, } 23.82 \pm 12.01 \text { vs. } 25.89 \pm \\
15.14 \text { in probiotic vs. placebo group } \\
\qquad(p=0.039)\end{array}$ & \\
\hline & & & & & & $\begin{array}{l}\text { C-reactive protein } \\
(\mathrm{mg} / \mathrm{L})(n=13 \mathrm{pts})\end{array}$ & $\begin{array}{c}\text { End of treatment, mean change }-5.32 \pm \\
19.7 \text { vs. } 8.55 \pm 20.1 \text { in probiotic vs. placebo } \\
\text { group }(p=0.24)\end{array}$ & \\
\hline & & & & & & QoL & $\begin{array}{l}\text { Improvement of QoL }(1.54 \pm 1.25) \text { during } \\
\text { probiotic group }(p<0.001)\end{array}$ & \\
\hline
\end{tabular}


Table 1. Cont.

\begin{tabular}{|c|c|c|c|c|c|c|c|c|}
\hline Study, Year (ref.) & $\begin{array}{l}\text { Inclusion Criteria } \\
\text { Exclusion Criteria }\end{array}$ & $\begin{array}{c}\text { Population } \\
\text { Characteristics }\end{array}$ & Intervention & Control & Duration & Outcome(s) & Results & Notes \\
\hline \multirow{3}{*}{$\begin{array}{l}\text { Guida et al., } \\
2014 \text { [13] }\end{array}$} & \multirow{3}{*}{$\begin{array}{l}\text { Stage 3-4 CKD patients } \\
\text { Renal transplant, severe } \\
\text { infections and } \\
\text { malnutrition, DM, } \\
\text { malignancy, food } \\
\text { intolerance, autoimmune } \\
\text { disorders }\end{array}$} & \multirow{3}{*}{$\begin{array}{c}n=30 \\
\text { Age }(\text { year })= \\
59.5 \pm 13.1 \\
\text { Men }(\%)=87 \\
\text { BMI }\left(\mathrm{Kg} / \mathrm{m}^{2}\right)=\sim 27.5 \\
\text { eGFR }(\mathrm{mL} / \mathrm{min}) \\
\quad=\sim 29.2\end{array}$} & \multirow{3}{*}{$\begin{array}{l}\text { Synbiotics } \\
\text { (5g powder } \\
\text { packets } \\
\text { thrice/daily) } \\
(n=18)\end{array}$} & \multirow{3}{*}{$\begin{array}{l}\text { Placebo } \\
(n=12)\end{array}$} & \multirow{3}{*}{$\begin{array}{c}\text { Four } \\
\text { weeks }\end{array}$} & & & \multirow{3}{*}{$\begin{array}{c}\text { Double blind } \\
\text { Synbiotic formulation } \\
\text { consisted of probiotic } \\
\text { supplement (L. plantarum, } 5 \\
\text { billion CFU, L. casei subsp. } \\
\text { Rhamnosus, } 2 \text { billion CFU, } L \text {. } \\
\text { gasseri, } 2 \text { billion CFU, } \\
\text { Bifidobacterium infantis, } 1 \text { billion } \\
\text { CFU, Bifidobacterium longum, } 1 \\
\text { billion CFU, L. acidophilus, } 1 \\
\text { billion CFU, L. salivarius, } 1 \\
\text { billion CFU, L. sporogenes, } 1 \\
\text { billion CFU and Streptococcus } \\
\text { thermophilus, } 5 \text { billion CFU) } \\
\text { and prebiotic inulin }(2.2 \mathrm{~g}) \text { and } \\
\text { tapioca-resistant starch }(1.3 \mathrm{~g} \text { ) }\end{array}$} \\
\hline & & & & & & eGFR (mL/min) & No difference between groups & \\
\hline & & & & & & $\begin{array}{l}\text { Total p-cresol } \\
(\mu \mathrm{g} / \mathrm{mL})\end{array}$ & $\begin{array}{c}\text { End of treatment, } 0.8 \text { (IQR 0.3-3.7) vs. } 3.9 \\
\text { (IQR 3.2-5.8) in synbiotic vs. placebo group } \\
(p<0.05)\end{array}$ & \\
\hline \multirow{4}{*}{$\begin{array}{l}\text { Ranganathan et al., } \\
2014[14]\end{array}$} & \multirow{4}{*}{$\begin{array}{l}\text { HIV, liver disease, drugs } \\
\text { or alcohol dependence, } \\
\text { anticoagulant therapy, } \\
\text { medical debilitating } \\
\text { disorder, pregnancy }\end{array}$} & \multirow{4}{*}{$\begin{array}{c}n=22 \\
\text { Age }(\text { year })=54 \\
(29-79) \\
\text { Men }(\%)=27 \\
\text { SBP }(\mathrm{mmHg})=148 \\
\text { DBP }(\mathrm{mmHg})=76\end{array}$} & \multirow{4}{*}{$\begin{array}{c}\text { Probiotics } \\
\text { (two capsules } \\
\text { /thrice daily) } \\
\quad(n=22)\end{array}$} & \multirow{4}{*}{$\begin{array}{l}\text { Placebo } \\
(n=22)\end{array}$} & \multirow{4}{*}{$\begin{array}{l}\text { Six } \\
\text { months }\end{array}$} & & & \multirow{4}{*}{$\begin{array}{l}\text { Each capsule of probiotic } \\
\text { formulation contained } 30 \\
\text { billion CFU of S. thermophilus, } \\
\text { L. acidophilus and B. longum } \\
\text { Six drop-outs; per-protocol } \\
\text { analysis performed }\end{array}$} \\
\hline & & & & & & $\begin{array}{l}\text { C-reactive protein } \\
(\mathrm{mg} / \mathrm{L})\end{array}$ & No difference between groups & \\
\hline & & & & & & $\begin{array}{c}\text { Total indoxyl } \\
\text { glucuronide }(\mathrm{mg} \%)\end{array}$ & No difference between groups & \\
\hline & & & & & & QoL-36 score & No difference between groups & \\
\hline \multirow{7}{*}{$\begin{array}{l}\text { Sirich et al., } \\
2014 \text { [15] }\end{array}$} & \multirow{7}{*}{$\begin{array}{c}\text { HD patients } \\
\text { Urea clearance }>2 \\
\mathrm{~mL} / \mathrm{min} \text {, active } \\
\text { gastrointestinal disease, } \\
\text { use of antibiotics within } \\
\text { four weeks before } \\
\text { study entry }\end{array}$} & \multirow{7}{*}{$\begin{array}{c}n=40 \\
\text { Age }(\text { year) }=\sim 56 \\
\text { Men }(\%)=\sim 60 \\
\text { HD vintage }(\text { year })= \\
\sim 4 \\
\text { BMI }\left(\text { Kg/m } / \mathrm{m}^{2}\right)=\sim 29 \\
\text { DM }(\%)=\sim 45\end{array}$} & \multirow{7}{*}{$\begin{array}{c}\text { Prebiotics } \\
\text { (resistant } \\
\text { starch, up to } \\
\text { two } \\
\text { sachets/day) } \\
\quad(n=20)\end{array}$} & \multirow{7}{*}{$\begin{array}{l}\text { Placebo } \\
(n=20)\end{array}$} & \multirow{7}{*}{ Six weeks } & Urea $(\mathrm{mg} / \mathrm{dL})$ & $\begin{array}{l}\text { End of treatment, } 56 \pm 14 \text { vs. } 60 \pm 19 \text { in } \\
\text { prebiotic vs. placebo group }(p>0.05)\end{array}$ & \multirow{3}{*}{$\begin{array}{c}\text { Single blind } \\
\text { Fiber sachets contained } 15 \mathrm{~g} \text { of } \\
\text { high-amylose corn starch (40\% } \\
\text { digestible and } 60 \% \text { resistant } \\
\text { starch); placebo sachets } \\
\text { contained } 15 \mathrm{~g} \text { of waxy corn } \\
\text { starch }\end{array}$} \\
\hline & & & & & & $\begin{array}{l}\text { C-reactive protein } \\
(\mathrm{mg} / \mathrm{dL})\end{array}$ & $\begin{array}{c}\text { End of treatment, } 1.1 \pm 1.6 \text { vs. } 0.8 \pm 1.1 \text { in } \\
\text { prebiotic vs. placebo group }(p>0.05)\end{array}$ & \\
\hline & & & & & & $\begin{array}{c}\text { Free indoxyl sulfate } \\
(\mathrm{mg} / \mathrm{dL})\end{array}$ & $\begin{array}{l}\text { End of treatment, } 0.25 \pm 0.17 \text { vs. } 0.28 \pm 0.15 \\
\text { in prebiotic vs. placebo group }(p>0.05)\end{array}$ & \\
\hline & & & & & & $\begin{array}{c}\text { Total indoxyl } \\
\text { sulfate }(\mathrm{mg} / \mathrm{dL})\end{array}$ & $\begin{array}{l}\text { End of treatment, } 2.9 \pm 1.4 \text { vs. } 3.1 \pm 1.2 \text { in } \\
\text { prebiotic vs. placebo group }(p>0.05)\end{array}$ & \multirow{2}{*}{$\begin{array}{l}\text { Two patients in control group } \\
\text { dropped out because of side } \\
\text { effects; no side effects in } \\
\text { treatment group }\end{array}$} \\
\hline & & & & & & $\begin{array}{l}\text { Free p-cresol } \\
(\mathrm{mg} / \mathrm{dL})\end{array}$ & $\begin{array}{l}\text { End of treatment, } 0.21 \pm 0.14 \text { vs. } 0.23 \pm 0.14 \\
\text { in prebiotic vs. placebo group }(p>0.05)\end{array}$ & \\
\hline & & & & & & $\begin{array}{l}\text { Total p-cresol } \\
(\mathrm{mg} / \mathrm{dL})\end{array}$ & $\begin{array}{l}\text { End of treatment, } 2.9 \pm 1.6 \text { vs. } 3.1 \pm 1.4 \text { in } \\
\text { prebiotic vs. placebo group }(p>0.05)\end{array}$ & \multirow{2}{*}{$\begin{array}{l}\text { Sixteen drop-outs (eight in } \\
\text { each group; per-protocol } \\
\text { analysis performed) }\end{array}$} \\
\hline & & & & & & QoL-36 score & No difference between groups & \\
\hline
\end{tabular}


Table 1. Cont.

\begin{tabular}{|c|c|c|c|c|c|c|c|c|}
\hline Study, Year (ref.) & $\begin{array}{l}\text { Inclusion Criteria } \\
\text { Exclusion Criteria }\end{array}$ & $\begin{array}{c}\text { Population } \\
\text { Characteristics }\end{array}$ & Intervention & Control & Duration & Outcome(s) & Results & Notes \\
\hline \multirow{5}{*}{$\begin{array}{l}\text { Firouzi et al., } \\
\quad 2015[7]\end{array}$} & \multirow{5}{*}{$\begin{array}{l}\text { Type } 2 \text { diabetic, mild } \\
\text { CKD patients } \\
\\
\text { Use of insulin, antibiotics } \\
\text { and/or other medication, } \\
\text { acute or chronic disease } \\
\text { other than DM, } \\
\text { hyperlipidemia and } \\
\text { hypertension }\end{array}$} & \multirow{5}{*}{$\begin{array}{c}n=136 \\
\text { Age }(\text { year })= \\
53.5 \pm 8.5 \\
\text { Men }(\%)=52 \\
\text { BMI }\left(\mathrm{kg} / \mathrm{m}^{2}\right)=\sim 29 \\
\text { eGFR }(\mathrm{mL} / \mathrm{min})= \\
\sim 74 \\
\text { Urea }(\mathrm{mmol} / \mathrm{L})=\sim 4.1 \\
\text { SCr }(\mu \mathrm{mol} / \mathrm{L})=\sim 71\end{array}$} & \multirow{5}{*}{$\begin{array}{l}\text { Probiotics } \\
\text { (60 billion } \\
\text { CFU/day) } \\
(n=68)\end{array}$} & \multirow{5}{*}{$\begin{array}{l}\text { Placebo } \\
(n=68)\end{array}$} & \multirow{5}{*}{12 weeks } & \multirow{3}{*}{ eGFR (mL/min) } & \multirow{3}{*}{$\begin{array}{l}\text { End of treatment, } 73.07 \pm 17.13 \text { vs. } 68.89 \pm \\
13.55 \text { in probiotic vs. placebo group } \\
\qquad(p=0.15)\end{array}$} & Double-blind \\
\hline & & & & & & & & $\begin{array}{l}\text { Probiotic supplementation } \\
\text { consisted of L. acidophilus, } L . \\
\text { casei, L. lactis, Bifidobacterium } \\
\text { bifidum, longum and infantis }\end{array}$ \\
\hline & & & & & & & & $\begin{array}{c}\text { Higher incidence of side effects } \\
\text { in probiotic }(8.7 \%) \text { than control } \\
\text { group }(3.7 \%)\end{array}$ \\
\hline & & & & & & $\mathrm{SCr}(\mu \mathrm{mol} / \mathrm{L})$ & $\begin{array}{l}\text { End of treatment, } 72.26 \pm 19.73 \text { vs. } 75.17 \pm \\
18.93 \text { in probiotic vs. placebo group }(p=0.3)\end{array}$ & $\begin{array}{l}\text { Thirty-five drop outs; ( } 15 \text { in } \\
\text { placebo and } 20 \text { in probiotic }\end{array}$ \\
\hline & & & & & & Urea $(\mathrm{mmol} / \mathrm{L})$ & $\begin{array}{l}\text { End of treatment, } 4.04 \pm 1.04 \text { vs. } 4.24 \pm 1.14 \\
\text { in probiotic vs. placebo group }(p<0.05)\end{array}$ & $\begin{array}{l}\text { group); ITT and per-protocol } \\
\text { analyses performed }\end{array}$ \\
\hline \multirow{6}{*}{$\begin{array}{l}\text { Viramontes-Horner } \\
\text { et al., 2015 [16] }\end{array}$} & \multirow{6}{*}{$\begin{array}{l}\text { HD patients, three } \\
\text { times/week, for at least } \\
\text { three months } \\
\\
\text { Current use of probiotics } \\
\text { for other reasons, } \\
\text { omega-3 fatty acids, } \\
\text { pentoxifylline, } \\
\text { immunosuppressive and } \\
\text { nonsteroidal } \\
\text { anti-inflammatory drugs, } \\
\text { cancer, HF, chronic liver } \\
\text { diseases, intestinal } \\
\text { malabsorption and active } \\
\text { infection, previous renal } \\
\text { transplant }\end{array}$} & \multirow{6}{*}{$\begin{array}{c}n=35 \\
\text { Age }(\text { year })=\sim 40 \\
\text { Men }(\%)=\sim 76.5 \\
\text { HD vintage }(\text { year })= \\
\sim 5 \\
\text { BMI }\left(\mathrm{Kg} / \mathrm{m}^{2}\right)=\sim 23.5 \\
\text { DM }(\%)=\sim 70 \\
\mathrm{HTN}(\%)=\sim 50 \\
\mathrm{SCr}(\mathrm{mg} / \mathrm{dL})=\sim 10.5\end{array}$} & \multirow{6}{*}{$\begin{array}{l}\text { Synbiotics } \\
\text { (11 million } \\
\text { CFU/day + } \\
2.31 \mathrm{~g} \text { inulin) } \\
(n=20)\end{array}$} & \multirow{6}{*}{$\begin{array}{l}\text { Placebo } \\
(n=15)\end{array}$} & \multirow{6}{*}{$\begin{array}{l}\text { Eight } \\
\text { weeks }\end{array}$} & $\mathrm{SCr}(\mathrm{mg} / \mathrm{dL})$ & $\begin{array}{c}\text { End of treatment, } 11.4 \text { (IQR 9.9-13.0) vs. } \\
10.4 \text { (IQR 9.0-13.2) in synbiotic vs. placebo } \\
\text { group }(p>0.05)\end{array}$ & \multirow{6}{*}{$\begin{array}{c}\text { Double blind } \\
\text { Synbiotic formulation } \\
\text { consisted of probiotic } \\
\text { supplement (L. acidophilus and } \\
\text { Bifidobacterium lactis) and } \\
\text { prebiotic inulin }(2.31 \mathrm{~g}), \\
\text { omega-3 fatty acids and } \\
\text { complex B-vitamins }(1.5 \mathrm{~g}) \\
\text { Patients underwent nutritional } \\
\text { counselling consisting of } \\
\text { energy ( } 30-35 \mathrm{kcal} / \mathrm{kg} / \text { day) } \\
\text { and protein }(1.1-1.2 \mathrm{~g} / \mathrm{kg} / \text { day) } \\
\text { intakes and potassium, } \\
\text { phosphorus, sodium restriction } \\
\text { Seven drop-outs; per-protocol } \\
\text { analysis performed }\end{array}$} \\
\hline & & & & & & Urea (mg/dL) & $\begin{array}{l}\text { End of treatment, } 148.6 \pm 41.6 \text { vs. } 131.5 \pm \\
43.8 \text { in synbiotic vs. placebo group }(p>0.05)\end{array}$ & \\
\hline & & & & & & $\begin{array}{l}\text { C-reactive protein } \\
(\mathrm{mg} / \mathrm{dL})\end{array}$ & $\begin{array}{l}\text { End of treatment, } 6.3 \text { (IQR 1.8-11.3) vs. } 5.0 \\
\text { (IQR 0.6-9.9) in synbiotic vs. placebo group } \\
(p>0.05)\end{array}$ & \\
\hline & & & & & & TNF- $\alpha(\mathrm{pg} / \mathrm{mL})$ & $\begin{array}{l}\text { End of treatment, } 2.9 \text { (IQR 0.9-6.7) vs. } 3.1 \\
\text { (IQR 0.0-3.7) in synbiotic vs. placebo group } \\
(p>0.05)\end{array}$ & \\
\hline & & & & & & IL-6 (pg/mL) & $\begin{array}{l}\text { End of treatment, } 2.0 \text { (IQR 1.2-3.9) vs. } 0.6 \\
\text { (IQR 0.2-3.6) in synbiotic vs. placebo group } \\
(p>0.05)\end{array}$ & \\
\hline & & & & & & $\begin{array}{l}\text { Nutritional status } \\
\quad(\text { SGA) }\end{array}$ & $\begin{array}{l}\text { End of treatment, } 1 / 20 \text { vs. } 4 / 15 \text { had mild to } \\
\text { moderate malnutrition in synbiotic vs. } \\
\text { placebo group }(p>0.05) \\
\text { End of treatment, } 19 / 20 \text { vs. } 11 / 15 \text { were well } \\
\text { nourished in synbiotic vs. placebo group } \\
(p>0.05)\end{array}$ & \\
\hline
\end{tabular}


Table 1. Cont.

\begin{tabular}{|c|c|c|c|c|c|c|c|c|}
\hline Study, Year (ref.) & $\begin{array}{l}\text { Inclusion Criteria } \\
\text { Exclusion Criteria }\end{array}$ & $\begin{array}{c}\text { Population } \\
\text { Characteristics }\end{array}$ & Intervention & Control & Duration & Outcome(s) & Results & Notes \\
\hline \multirow{9}{*}{$\begin{array}{l}\text { Wang et al., } \\
2015 \text { [17] }\end{array}$} & \multirow{9}{*}{$\begin{array}{l}\text { PD patients with eGFR } \\
<15 \mathrm{~mL} / \mathrm{min} / 1.73 \mathrm{~m}^{2} \\
\\
\text { Infectious diseases in the } \\
\text { previous month, } \\
\text { autoimmune diseases, } \\
\text { use of } \\
\text { immunosuppressive } \\
\text { agents or antibiotics } \\
\text { within one month prior } \\
\text { to enrollment, pregnancy }\end{array}$} & \multirow{9}{*}{$\begin{array}{c}n=39 \\
\text { Age }(\text { year })=\sim 52 \\
\text { Men }(\%)=\sim 46 \\
\text { PD vintage }(\mathrm{mo})= \\
\sim 42 \\
\text { BMI }\left(\mathrm{Kg} / \mathrm{m}^{2}\right)=\sim 23 \\
\text { DM }(\%)=\sim 21 \\
\mathrm{HTN}(\%)=\sim 81.3 \\
\mathrm{CAD}(\%)=\sim 21 \\
\mathrm{SCr}(\mathrm{mg} / \mathrm{dL})=\sim 12.5 \\
\text { Urea }(\mathrm{mg} / \mathrm{dL})=\sim 58\end{array}$} & \multirow{9}{*}{$\begin{array}{l}\text { Probiotics } \\
\text { (4 billion } \\
\text { CFU/day) } \\
(n=21)\end{array}$} & \multirow{9}{*}{$\begin{array}{l}\text { Placebo } \\
(n=18)\end{array}$} & \multirow{9}{*}{$\begin{array}{l}\text { Six } \\
\text { months }\end{array}$} & $\underset{\left.\mathrm{m}^{2}\right)}{\mathrm{CrCl}(\mathrm{mL} / \mathrm{min} / 1.73}$ & $\begin{array}{l}\text { End of treatment, } 1.59 \text { (IQR } 0.85-2.93 \text { ) vs. } \\
1.24 \text { (IQR 0.50-2.74) in probiotic vs. placebo } \\
\text { group }(p>0.05)\end{array}$ & \multirow{9}{*}{$\begin{array}{c}\text { Double blind } \\
\text { One capsule of probiotics } \\
\text { consisted of } 1 \text { billion CFU pe } \\
\text { bacterium strain } \\
\text { (Bifidobacterium bifidum, } \\
\text { catenulatum, longum and } L . \\
\text { plantarum) } \\
\text { Eight drop-outs; per protoco } \\
\text { analysis performed }\end{array}$} \\
\hline & & & & & & $\mathrm{SCr}(\mathrm{mg} / \mathrm{dL})$ & $\begin{array}{c}\text { End of treatment, } 11.76 \text { (IQR 9.55-13.86) vs. } \\
12.84 \text { (IQR 11.84-14.23) in probiotic vs. } \\
\text { placebo group }(p>0.05)\end{array}$ & \\
\hline & & & & & & Urea $(\mathrm{mg} / \mathrm{dL})$ & $\begin{array}{l}\text { End of treatment, } 57.0 \text { (IQR 50.0-63.0) vs. } \\
55.5 \text { (IQR 48.0-71.0) in probiotic vs. placebo } \\
\text { group }(p>0.05)\end{array}$ & \\
\hline & & & & & & TNF- $\alpha(\mathrm{pg} / \mathrm{mL})$ & $\begin{array}{c}\text { End of treatment, } 0.74 \text { (IQR 0.41-1.29) vs. } \\
0.74 \text { (IQR 0.18-2.22) in probiotic vs. placebo } \\
\text { group }(p>0.05)\end{array}$ & \\
\hline & & & & & & $\mathrm{IFN}-\gamma(\mathrm{pg} / \mathrm{mL})$ & $\begin{array}{l}\text { End of treatment, } 7 \text { (IQR 4-12) vs. } 8.67 \text { (IQR } \\
2-18.66) \text { in probiotic vs. placebo group } \\
(p>0.05)\end{array}$ & \\
\hline & & & & & & IL-5 (pg/mL) & $\begin{array}{l}\text { End of treatment, } 9.19 \text { (IQR 7.68-12.61) vs. } \\
9.6 \text { (IQR 7.99-12.6) in probiotic vs. placebo } \\
\text { group }(p>0.05)\end{array}$ & \\
\hline & & & & & & IL-6 (pg/mL) & $\begin{array}{c}\text { End of treatment, } 1.12 \text { (IQR 0.75-3.93) vs. } \\
0.95 \text { (IQR 0.11-1.7) in probiotic vs. placebo } \\
\text { group ( } p>0.05 \text { ) }\end{array}$ & \\
\hline & & & & & & $\mathrm{IL}-10(\mathrm{pg} / \mathrm{mL})$ & $\begin{array}{c}\text { End of treatment, } 15.97 \text { (IQR 13.47-23.17) vs. } \\
12.69 \text { (IQR 10.25-20.02) in probiotic vs. } \\
\text { placebo group }(p>0.05)\end{array}$ & \\
\hline & & & & & & IL-17 (pg/mL) & $\begin{array}{l}\text { End of treatment, } 1.61 \text { (IQR 0.98-2.2) vs. } \\
2.13 \text { (IQR 1.61-3.8) in probiotic vs. placebo } \\
\text { group }(p>0.05)\end{array}$ & \\
\hline \multirow{4}{*}{$\begin{array}{l}\text { Dehghani et al., } \\
2016[5]\end{array}$} & \multirow{4}{*}{$\begin{array}{l}\text { Stage 3-4 CKD patients } \\
\text { HD, use of antibiotics } \\
\text { and lactulose two weeks } \\
\text { before study entry, } \\
\text { alcohol dependence, } \\
\text { hepatitis or HIV infection, } \\
\text { pregnancy }\end{array}$} & \multirow{4}{*}{$\begin{array}{c}n=66 \\
\text { Age }(\mathrm{yr})=61.0 \pm 7.65 \\
\text { Men }(\%)=75.8 \\
\text { BMI }\left(\mathrm{Kg} / \mathrm{m}^{2}\right)=28.5 \\
\pm 4.1 \\
\operatorname{DM}(\%)=98.5 \\
\mathrm{HTN}(\%)=84.6 \\
\mathrm{SCr}(\mathrm{mg} / \mathrm{dL})=\sim 2.1 \\
\text { eGFR }(\mathrm{mL} / \mathrm{min} / 1.73 \\
\left.\mathrm{m}^{2}\right)=\sim 41.4 \\
\text { Urea }(\mathrm{mg} / \mathrm{dL})=\sim 39\end{array}$} & \multirow{4}{*}{$\begin{array}{c}\text { Synbiotics } \\
\text { (two } \\
\text { capsules/twice } \\
\text { daily) } \\
(n=31)\end{array}$} & \multirow{4}{*}{$\begin{array}{l}\text { Placebo } \\
(n=35)\end{array}$} & \multirow{4}{*}{ Six weeks } & $\begin{array}{l}\text { Non-fatal CV } \\
\text { events }\end{array}$ & $\begin{array}{l}1 / 31 \text { vs. } 0 / 35 \text { in synbiotic vs. placebo group } \\
\qquad(p>0.05)\end{array}$ & \multirow{4}{*}{$\begin{array}{l}\text { Two capsules }(500 \mathrm{mg}) \text { of } \\
\text { synbiotic supplement consisted } \\
\text { of seven strains of probiotics ( } L \\
\text { casei, L. acidophilus, } L \text {. } \\
\text { bulgarigus, L. rhamnosus, } \\
\text { Bifidobacterium breve, longum, } \\
\text { Streptococcus thermophilus) and } \\
\text { prebiotic } \\
\text { fructo-oligosaccharides } \\
\text { Nine drop-outs; per protocol } \\
\text { analysis performed }\end{array}$} \\
\hline & & & & & & $\begin{array}{c}\text { eGFR } \\
\left(\mathrm{mL} / \mathrm{min} / 1.73 \mathrm{~m}^{2}\right)\end{array}$ & $\begin{array}{l}\text { End of treatment, } 43.25 \pm 17.49 \text { vs. } 39.51 \pm \\
17.64 \text { in synbiotic vs. placebo group } \\
(p=0.90)\end{array}$ & \\
\hline & & & & & & $\mathrm{SCr}(\mathrm{mg} / \mathrm{dL})$ & $\begin{array}{l}\text { End of treatment, } 1.90 \pm 0.70 \text { vs. } 2.18 \pm 1.14 \\
\text { in synbiotic vs. placebo group }(p=0.15)\end{array}$ & \\
\hline & & & & & & Urea (mg/dL) & $\begin{array}{c}\text { End of treatment, } 36.14 \pm 20.52 \text { vs. } 39.62 \pm \\
27.56 \text { in synbiotic vs. placebo } \\
\text { group; } p=0.006\end{array}$ & \\
\hline
\end{tabular}


Table 1. Cont.

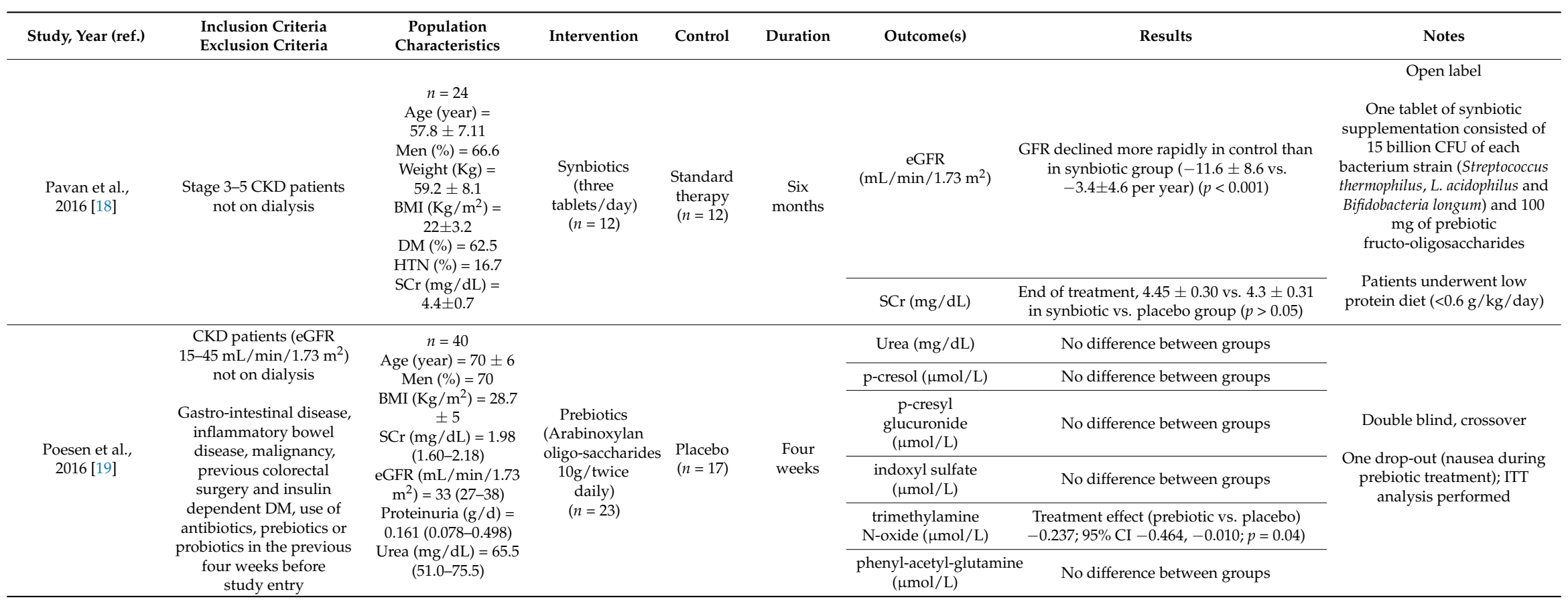


Table 1. Cont.

\begin{tabular}{|c|c|c|c|c|c|c|c|c|}
\hline Study, Year (ref.) & $\begin{array}{l}\text { Inclusion Criteria } \\
\text { Exclusion Criteria }\end{array}$ & $\begin{array}{c}\text { Population } \\
\text { Characteristics }\end{array}$ & Intervention & Control & Duration & Outcome(s) & Results & Notes \\
\hline \multirow{14}{*}{$\begin{array}{l}\text { SYNERGY } \\
2016^{*}[20-22]\end{array}$} & \multirow{14}{*}{$\begin{array}{l}\text { Moderate to severe } \\
\text { (pre-HD), hypertensive } \\
\text { CKD patients } \\
\\
\text { Previous renal transplant, } \\
\text { bowel resection or bowel } \\
\text { radiation recipient, bowel } \\
\text { syndrome, Crohn disease } \\
\text { or ulcerative colitis, likely } \\
\text { to receive a transplant or } \\
\text { progress to dialysis } \\
\text { within six months, pre, } \\
\text { probiotics or antibiotic } \\
\text { use within one month, or } \\
\text { change in } \\
\text { immunosuppressant dose } \\
\text { within six months before } \\
\text { study entry }\end{array}$} & \multirow{14}{*}{$\begin{array}{c}n=31 \\
\text { Age (year) }=69 \pm 9 \\
\text { Men }(\%)=61 \\
\text { BMI }\left(\mathrm{Kg} / \mathrm{m}^{2}\right)= \\
28 \pm 6 \\
\text { eGFR }(\mathrm{mL} / \mathrm{min} / 1.73 \\
\left.\mathrm{m}^{2}\right)=25 \pm 8 \\
\text { Proteinuria }(\mathrm{mg} / \text { day }) \\
=296(168-1100) \\
\text { Albuminuria } \\
\text { (mg } / \text { day })=97 \\
(21-677)\end{array}$} & \multirow{14}{*}{$\begin{array}{c}\text { Synbiotic } \\
\text { supplements } \\
\text { (15 g powder + } \\
\text { two } \\
\text { capules/day) } \\
(n=13)\end{array}$} & \multirow{14}{*}{$\begin{array}{l}\text { Placebo } \\
(n=18)\end{array}$} & \multirow{14}{*}{16 weeks } & $\begin{array}{c}\text { eGFR } \\
\left(\mathrm{mL} / \mathrm{min} / 1.73 \mathrm{~m}^{2}\right)\end{array}$ & $\begin{array}{l}\text { End of treatment, } 24 \pm 8 \text { vs. } 24 \pm 8 \text { in } \\
\text { synbiotic vs. placebo group }(p=0.67)\end{array}$ & \multirow{14}{*}{$\begin{array}{l}\text { Double blind, crossover } \\
\text { Participants underwent a two } \\
\text { week run-in period (dietary } \\
\text { education with stable protein } \\
\text { and fiber intakes) before } \\
\text { randomization } \\
\text { Synbiotic formulation } \\
\text { consisted of } 15 \mathrm{~g} \text { prebiotic (a } \\
\text { combination of high-molecular } \\
\text { weight inulin, } \\
\text { fructo-oligosaccharides and } \\
\text { galacto-oligosaccharides) and } \\
90 \text { billion CFU probiotic } \\
\text { component (capsule) including } \\
\text { nine different strains across the } \\
\text { Lactobacillus, Bifidobacteria and } \\
\text { Streptococcus genera } \\
\text { Six drop-outs; per protocol } \\
\text { analysis performed }\end{array}$} \\
\hline & & & & & & $\mathrm{SCr}(\mu \mathrm{mol} / \mathrm{L})$ & $\begin{array}{l}\text { End of treatment, } 231 \pm 75 \text { vs. } 233 \pm 74 \text { in } \\
\text { synbiotic vs. placebo group }(p=0.94)\end{array}$ & \\
\hline & & & & & & $\begin{array}{l}\text { Proteinuria } \\
\text { (mg/day) }\end{array}$ & $\begin{array}{l}\text { End of treatment, } 369 \text { (IQR 162-1550) vs. } \\
323 \text { (IQR 169-1150) in synbiotic vs. placebo } \\
\text { group }(p=0.20)\end{array}$ & \\
\hline & & & & & & $\begin{array}{l}\text { Albuminuria } \\
\text { (mg/day) }\end{array}$ & $\begin{array}{l}\text { End of treatment, } 112 \text { (IQR 16-758) vs. } 111 \\
\text { (IQR 12-594) in synbiotic vs. placebo group } \\
(p>0.05)\end{array}$ & \\
\hline & & & & & & $\mathrm{IL}-1 \beta(\mathrm{pg} / \mathrm{mL})$ & $\begin{array}{l}\text { End of treatment, } 0.8 \pm 0.7 \text { vs. } 0.8 \pm 0.6 \text { in } \\
\text { synbiotic vs. placebo group }(p=0.98)\end{array}$ & \\
\hline & & & & & & IL-6 $(\mathrm{pg} / \mathrm{mL})$ & $\begin{array}{l}\text { End of treatment, } 2.2 \pm 0.9 \text { vs. } 2.0 \pm 0.8 \text { in } \\
\text { synbiotic vs. placebo group }(p=0.40)\end{array}$ & \\
\hline & & & & & & $\mathrm{IL}-10(\mathrm{pg} / \mathrm{mL})$ & $\begin{array}{l}\text { End of treatment, } 3.6 \pm 2.0 \text { vs. } 3.6 \pm 2.1 \text { in } \\
\text { synbiotic vs. placebo group }(p=0.84)\end{array}$ & \\
\hline & & & & & & $\mathrm{TNF}-\alpha(\mathrm{pg} / \mathrm{mL})$ & $\begin{array}{l}\text { End of treatment, } 2.2 \pm 0.8 \text { vs. } 2.0 \pm 0.7 \text { in } \\
\text { synbiotic vs. placebo group }(p=0.09)\end{array}$ & \\
\hline & & & & & & $\begin{array}{c}\text { Free indoxyl sulfate } \\
(\mu \mathrm{mol} / \mathrm{L})\end{array}$ & $\begin{array}{l}\text { End of treatment, } 0.6 \text { (IQR } 0.4-0.8 \text { ) vs. } 0.5 \\
\text { (IQR 0.4-1.0) in synbiotic vs. placebo group } \\
(p=0.20)\end{array}$ & \\
\hline & & & & & & $\begin{array}{c}\text { Total indoxyl } \\
\text { sulfate }(\mu \mathrm{mol} / \mathrm{L})\end{array}$ & $\begin{array}{l}\text { End of treatment, } 15 \text { (IQR 10-26) vs. } 16 \text { (IQR } \\
12-27 \text { ) in synbiotic vs. placebo group ( } p= \\
0.12 \text { ) }\end{array}$ & \\
\hline & & & & & & $\begin{array}{l}\text { Free } \mathrm{p} \text {-cresol } \\
(\mu \mathrm{mol} / \mathrm{L})\end{array}$ & $\begin{array}{l}\text { End of treatment, } 2.2 \text { (IQR 0.7-2.8) vs. } 2.4 \\
\text { (IQR 1.1-3.4) in synbiotic vs. placebo group } \\
(p=0.34)\end{array}$ & \\
\hline & & & & & & $\begin{array}{l}\text { Total p-cresol } \\
(\mu \mathrm{mol} / \mathrm{L})\end{array}$ & $\begin{array}{l}\text { End of treatment, } 75 \text { (IQR 36-101) vs. } 93 \\
\text { (IQR 54-136) in synbiotic vs. placebo group } \\
(p=0.03)\end{array}$ & \\
\hline & & & & & & $\begin{array}{c}\text { Physical } \\
\text { patient-reported } \\
\text { health score }\end{array}$ & $\begin{array}{l}\text { End of treatment, } 35 \pm 11 \text { vs. } 37 \pm 10 \text { in } \\
\text { synbiotic vs. placebo group }(p=0.23)\end{array}$ & \\
\hline & & & & & & $\begin{array}{l}\text { Mental } \\
\text { patient-reported } \\
\text { health score }\end{array}$ & $\begin{array}{l}\text { End of treatment, } 51 \pm 10 \text { vs. } 52 \pm 9 \text { in } \\
\text { synbiotic vs. placebo group }(p=0.75)\end{array}$ & \\
\hline
\end{tabular}


Table 1. Cont.

\begin{tabular}{|c|c|c|c|c|c|c|c|c|}
\hline Study, Year (ref.) & $\begin{array}{l}\text { Inclusion Criteria } \\
\text { Exclusion Criteria }\end{array}$ & $\begin{array}{c}\text { Population } \\
\text { Characteristics }\end{array}$ & Intervention & Control & Duration & Outcome(s) & Results & Notes \\
\hline \multirow{3}{*}{$\begin{array}{l}\text { Guida et al., } \\
2017 \text { [23] }\end{array}$} & \multirow{3}{*}{$\begin{array}{l}\text { Kidney transplanted } \\
\text { patients with stable graft } \\
\text { function } \\
\text { Acute rejection or } \\
\text { infection in the previous } \\
\text { thriee months, DM, } \\
\text { malignancy, pregnancy, } \\
\text { food intolerance, } \\
\text { autoimmune disorders, } \\
\text { severe malnutrition or } \\
\text { clinical conditions } \\
\text { requiring } \\
\text { artificial feeding }\end{array}$} & \multirow{3}{*}{$\begin{array}{c}n=34 \\
\text { Age }(\text { year })=\sim 50.6 \\
\text { Men }(\%)=\sim 82.3 \\
\text { Weight }(\mathrm{Kg})=\sim 75.6 \\
\text { WC }(\mathrm{cm})=\sim 94.7 \\
\text { BMI }\left(\mathrm{Kg} / \mathrm{m}^{2}\right)=\sim 25.4 \\
\text { eGFR }(\mathrm{mL} / \mathrm{min} / 1.73 \\
\left.\mathrm{m}^{2}\right)=\sim 54.5\end{array}$} & \multirow{3}{*}{$\begin{array}{c}\text { Synbiotic } \\
\text { supplements } \\
\text { (three } \\
\text { times/day) } \\
(n=22)\end{array}$} & \multirow{3}{*}{$\begin{array}{l}\text { Placebo } \\
(n=12)\end{array}$} & \multirow{3}{*}{$\begin{array}{l}\text { Four } \\
\text { weeks }\end{array}$} & & & \multirow{3}{*}{$\begin{array}{l}\text { Synbiotic (Probinul Neutro) } \\
\text { consisted of probiotic } \\
\text { supplement (L. plantarum, } 5 \\
\text { billion CFU, L. casei subsp. } \\
\text { Rhamnosus, } 2 \text { billion CFU, } L \text {. } \\
\text { gasseri, } 2 \text { billion CFU, } \\
\text { Bifidobacterium infantis, } 1 \text { billion } \\
\text { CFU, B. longum, } 1 \text { Streptococcus } \\
\text { thermophilus, } 5 \text { billion CFU) } \\
\text { and prebiotic inulin }(2.2 \mathrm{~g} \text { ) and } \\
\text { tapioca-resistant starch (1.3 g) } \\
\text { Two drop-outs; per protocol } \\
\text { analysis performed }\end{array}$} \\
\hline & & & & & & $\begin{array}{c}\text { eGFR } \\
\left(\mathrm{mL} / \mathrm{min} / 1.73 \mathrm{~m}^{2}\right)\end{array}$ & $\begin{array}{l}\text { End of treatment, } 53.5 \pm 16.0 \text { vs. } 57.3 \pm 22.1 \\
\text { in synbiotic vs. placebo group }(p>0.05)\end{array}$ & \\
\hline & & & & & & $\begin{array}{l}\text { Total p-cresol } \\
(\mu \mathrm{g} / \mathrm{mL})\end{array}$ & $\begin{array}{c}\text { End of treatment, } 2.3 \text { (IQR 0.9-2.72) vs. } 4.4 \\
\text { (IQR 3.0-6.4) in synbiotic vs. placebo group; } \\
p<0.01\end{array}$ & \\
\hline $\begin{array}{l}\text { Miraghajani et al., } \\
\quad 2017 \text { [24] }\end{array}$ & $\begin{array}{c}\text { Type } 2 \text { diabetic patients } \\
\text { with early CKD } \\
\text { (proteinuria }>300 \\
\mathrm{mg} / \text { day and eGFR }>90 \\
\mathrm{~mL} / \mathrm{min} \text { ) } \\
\\
\text { Intolerance to soy milk, } \\
\text { smoking, alcoholism, } \\
\text { recent antibiotic therapy } \\
\text { and use of supplements } \\
\text { containing vitamins and } \\
\text { minerals, inflammatory } \\
\text { bowel disease, infection, } \\
\text { liver disease and } \\
\text { rheumatoid arthritis }\end{array}$ & $\begin{array}{c}n=40 \\
\text { Age }(\text { year) }=\sim 55.2 \\
\text { Men }(\%)=\sim 47.5 \\
\text { Weight }(\mathrm{Kg})=\sim 71 \\
\text { BMI }\left(\mathrm{Kg} / \mathrm{m}^{2}\right)=\sim 26.5\end{array}$ & $\begin{array}{l}\text { Probiotics } \\
\text { (2 billion } \\
\text { CFU/day) } \\
(n=20)\end{array}$ & $\begin{array}{l}\text { Placebo } \\
(n=20)\end{array}$ & $\begin{array}{l}\text { Eight } \\
\text { weeks }\end{array}$ & $\begin{array}{l}\text { Progranulin } \\
\text { (ng/mL) }\end{array}$ & $\begin{array}{c}\text { End of treatment, } 180.90 \pm 69.25 \text { vs. } 399.56 \\
\pm 105.20 \text { in probiotic vs. control group; } p= \\
0.01\end{array}$ & $\begin{array}{c}\text { Double blind } \\
\\
\text { Participants received } \\
\text { individualized dietary } \\
\text { counselling (restricted dietary } \\
\text { protein, sodium, and } \\
\text { potassium intake) before } \\
\text { randomization to a diet } \\
\text { containing } 200 \mathrm{~mL} / \mathrm{day} \\
\text { probiotic soy milk (fortified } \\
\text { with } 20 \text { million CFU } / \mathrm{mL} \text { of } L \text {. } \\
\text { plantarum) or conventional soy } \\
\text { milk }\end{array}$ \\
\hline
\end{tabular}


Table 1. Cont.

\begin{tabular}{|c|c|c|c|c|c|c|c|c|}
\hline Study, Year (ref.) & $\begin{array}{l}\text { Inclusion Criteria } \\
\text { Exclusion Criteria }\end{array}$ & $\begin{array}{c}\text { Population } \\
\text { Characteristics }\end{array}$ & Intervention & Control & Duration & Outcome(s) & Results & Notes \\
\hline \multirow{5}{*}{$\begin{array}{l}\text { Soleimani et al., } \\
2017 \text { [6] }\end{array}$} & \multirow{5}{*}{$\begin{array}{l}\text { Diabetic HD patients, } \\
\text { three times/week, for at } \\
\text { least one year } \\
\text { Intestinal diseases, use of } \\
\text { probiotic supplements, } \\
\text { prebiotic, antioxidant and } \\
\text { anti-inflammatory } \\
\text { supplements (vitamin E, } \\
\text { C and omega-3 fatty } \\
\text { acids), antibiotics and } \\
\text { immunosuppressive } \\
\text { medications within three } \\
\text { months before } \\
\text { enrolment, pregnancy }\end{array}$} & \multirow{5}{*}{$\begin{array}{c}n=60 \\
\text { Age }(\text { year })=\sim 56.7 \\
\text { Men }(\%)=66.7 \\
\text { Weight }(\mathrm{Kg})=\sim 68.3 \\
\text { BMI }\left(\mathrm{Kg} / \mathrm{m}^{2}\right)=\sim 26.3 \\
\text { HD vintage }(\text { year })= \\
\sim 3.5 \\
\text { HTN }(\%)=96.7 \\
\text { SCr }(\mathrm{mg} / \mathrm{dL})=\sim 7.6 \\
\text { eGFR }(\mathrm{mL} / \mathrm{min} / 1.73 \\
\left.\mathrm{m}^{2}\right)=\sim 2.35 \\
\text { hs-CRP }(\mathrm{ng} / \mathrm{mL})= \\
7672 \\
\text { Urea }(\mathrm{mg} / \mathrm{dL})=\sim 59.2 \\
\text { CVD }(\%)=\sim 21.6 \\
\text { CAD }(\%)=\sim 78.3\end{array}$} & \multirow{5}{*}{$\begin{array}{l}\text { Probiotics } \\
\text { (6 billion } \\
\text { CFU/day) } \\
(n=30)\end{array}$} & \multirow{5}{*}{$\begin{array}{l}\text { Placebo } \\
(n=30)\end{array}$} & \multirow{5}{*}{12 weeks } & $\begin{array}{c}\text { eGFR } \\
\left(\mathrm{mL} / \mathrm{min} / 1.73 \mathrm{~m}^{2}\right)\end{array}$ & $\begin{array}{l}\text { End of treatment, } 2.54 \pm 1.16 \text { vs. } 2.25 \pm 0.93 \\
\text { in probiotic vs. placebo group }(p=0.77)\end{array}$ & \multirow{5}{*}{$\begin{array}{c}\text { Double blind } \\
\text { Probiotic supplementation } \\
\text { consisted of L. acidophilus, } L \text {. } \\
\text { casei and Bifidobacterium } \\
\text { bifidum, } 2 \text { billion CFU/day per } \\
\text { strain } \\
\text { Five drop-outs; ITT analysis } \\
\text { performed }\end{array}$} \\
\hline & & & & & & $\mathrm{SCr}(\mathrm{mg} / \mathrm{dL})$ & $\begin{array}{l}\text { End of treatment, } 7.2 \pm 2.6 \text { vs. } 7.7 \pm 2.9 \text { in } \\
\text { probiotic vs. placebo group }(p=0.73)\end{array}$ & \\
\hline & & & & & & Urea $(\mathrm{mg} / \mathrm{dL})$ & $\begin{array}{l}\text { End of treatment, } 63.9 \pm 26.0 \text { vs. } 52.3 \pm 12.7 \\
\text { in probiotic vs. placebo group }(p=0.96)\end{array}$ & \\
\hline & & & & & & $\begin{array}{c}\text { hs-C-reactive } \\
\text { protein }(\mathrm{ng} / \mathrm{mL})\end{array}$ & $\begin{array}{c}\text { End of treatment, } 6110 \pm 4812.5 \text { vs. } 7555.7 \\
\pm 5316.2 \text { in probiotic vs. placebo group; } p= \\
0.03\end{array}$ & \\
\hline & & & & & & $\begin{array}{l}\text { Subjective global } \\
\text { assessment (SGA) } \\
\text { score }\end{array}$ & $\begin{array}{l}\text { End of treatment, } 8.8 \pm 2.0 \text { vs. } 10.2 \pm 3.7 \text { in } \\
\quad \text { probiotic vs. placebo group; } p=0.01\end{array}$ & \\
\hline \multirow{8}{*}{$\begin{array}{l}\text { Borges et al., } \\
2018[25]\end{array}$} & \multirow{8}{*}{$\begin{array}{l}\text { HD patients, three } \\
\text { times/week, for at least } \\
\text { six months } \\
\\
\text { Inflammatory and } \\
\text { autoimmune diseases, } \\
\text { AIDS, cancer, smokers, } \\
\text { HD with central catheter } \\
\text { access, pregnancy, use of } \\
\text { catabolic drugs, } \\
\text { antioxidant vitamin } \\
\text { supplements, pre-, pro-, } \\
\text { synbiotic and antibiotics } \\
\text { in the previous three } \\
\text { months before } \\
\text { study entry }\end{array}$} & \multirow{8}{*}{$\begin{array}{c}n=33 \\
\text { Age }(\text { year })=\sim 52 \\
\text { Men }(\%)=\sim 63.6 \\
\text { WC }(\mathrm{cm})=\sim 92 \\
\text { BMI }\left(\mathrm{Kg} / \mathrm{m}^{2}\right)=\sim 25.2 \\
\text { HD vintage (month) } \\
=\sim 48.3\end{array}$} & \multirow{8}{*}{$\begin{array}{c}\text { Probiotics } \\
\text { (90 billion } \\
\text { CFU/day) } \\
(n=16)\end{array}$} & \multirow{8}{*}{$\begin{array}{l}\text { Placebo } \\
(n=17)\end{array}$} & \multirow{8}{*}{12 weeks } & $\mathrm{SCr}(\mathrm{mg} / \mathrm{dL})$ & $\begin{array}{l}\text { End of treatment, } 9.6 \pm 7.7 \text { vs. } 10.3 \pm 0.6 \text { in } \\
\text { probiotic vs. placebo group }(p=0.66)\end{array}$ & \multirow{8}{*}{$\begin{array}{c}\text { Double blind } \\
\text { Probiotic supplementation } \\
\text { consisted of Streptococcus } \\
\text { thermophilus, L. acidophilus and } \\
\text { Bifidobacteria longum } \\
\text { Tirtheen drop-outs; } \\
\text { per-protocol analysis } \\
\text { performed }\end{array}$} \\
\hline & & & & & & $\begin{array}{l}\text { Urea pre-HD } \\
(\mathrm{mg} / \mathrm{dL})\end{array}$ & $\begin{array}{l}\text { End of treatment, } 172.6 \pm 45.0 \text { vs. } 155.9 \pm \\
38.6 \text { in probiotic vs. placebo group }(p=0.37)\end{array}$ & \\
\hline & & & & & & $\begin{array}{l}\text { Urea post-HD } \\
(\mathrm{mg} / \mathrm{dL})\end{array}$ & $\begin{array}{l}\text { End of treatment, } 51.3 \pm 19.7 \text { vs. } 49.5 \pm 12.7 \\
\text { in probiotic vs. placebo group }(p=0.54)\end{array}$ & \\
\hline & & & & & & $\begin{array}{l}\text { C-reactive protein } \\
(\mathrm{mg} / \mathrm{dL})\end{array}$ & $\begin{array}{l}\text { End of treatment, } 5.5(95 \% \text { CI } 2.8,11.7) \text { vs. } \\
1.7(95 \% \text { CI } 0.8,6.4) \text { in probiotic vs. placebo } \\
\text { group }(p=0.47)\end{array}$ & \\
\hline & & & & & & IL-6 (pg/mL) & $\begin{array}{l}\text { End of treatment, } 38.4 \pm 20.1 \mathrm{vs} .30 .3 \pm 18.5 \\
\text { in probiotic vs. placebo group }(p=0.91)\end{array}$ & \\
\hline & & & & & & $\begin{array}{l}\text { Total indoxyl } \\
\text { sulfate }(\mathrm{mg} / \mathrm{L})\end{array}$ & $\begin{array}{l}\text { End of treatment, } 36.5 \pm 15 \text { vs. } 42.5 \pm 11.0 \\
\text { in probiotic vs. placebo group }(p=0.60)\end{array}$ & \\
\hline & & & & & & $\begin{array}{c}\text { Total p-cresol } \\
(\mathrm{mg} / \mathrm{L})\end{array}$ & $\begin{array}{l}\text { End of treatment, } 46.3 \pm 32.7 \text { vs. } 57.5 \pm 29.8 \\
\text { in probiotic vs. placebo group }(p=0.83)\end{array}$ & \\
\hline & & & & & & $\begin{array}{c}\text { Total indole-3 } \\
\text { acetic-acid }(\mu \mathrm{g} / \mathrm{L})\end{array}$ & $\begin{array}{l}\text { End of treatment, } 456.8 \pm 199 \text { vs. } 744.9 \pm \\
309 \text { in probiotic vs. placebo group }(p=0.45)\end{array}$ & \\
\hline
\end{tabular}

Legend AIDS: acquired immune deficiency syndrome; BMI: body mass index; BUN: blood urea nitrogen; CAD: coronary artery disease; CFU: colony forming units; CI: confidence interval; CKD: chronic kidney disease; CrCl: creatinine clearance; hs-CRP: high sensitive C-reactive protein; CV: cardiovascular; CVD: cardiovascular disease; DBP: diastolic blood pressure; DM: diabetes mellitus; eGFR: estimated glomerular filtration rate; HD: hemodialysis; HF: heart failure; HIV: human immunodeficiency virus; HTN: hypertension; IFN: interferon; IL: interleukin; IQR: interquartile range; ITT: intention to treat; PD: peritoneal dialysis; QoL: quality of life; RCT: randomized clinical trial; SBP: systolic blood pressure; SCr: serum creatinine; SGA: subjective global assessment; TNF: tumor necrosis factor; WC: waist circumference; *: main study. 


\subsection{Study Characteristics}

All but six studies reviewed $[10-12,14,19,20]$ had a parallel design. Study participants had early renal failure (NKF KDOQI stage 1-2) in two RCTs [7,24], mild-to-moderate (stage 3-4) CKD in four $[5,12,13,18]$ and moderate-to-severe (stage $4-5)$ in three $[11,19,20]$. One study [10] recruited CKD patients with a mean serum creatinine of $4.4 \pm 0.8 \mathrm{mg} / \mathrm{dL}$ with no information on GFR. One study [23] included kidney transplant recipients with stable graft function. Five studies [6,14-16,25] focused on hemodialysis (HD) patients and one [17] on peritoneal dialysis (PD) patients. The prevalence of diabetes spanned from $21 \%$ [17] to $100 \%$ [6,7,24] while that of hypertension ranged from $16.7 \%$ [18] to $96.7 \%$ [6]. The number of participants varied from nine [11] to 136 [7]. The mean age of patients ranged from $~ 40$ [16] to 70 years [19]. Male gender spanned from $27 \%$ [14] to $87 \%$ [13]. Study follow-up varied from four weeks $[13,19,23]$ to six months $[12,14,17,18]$.

\subsection{Risk of Bias}

Risk of bias of randomized controlled trials is summarized in Table 2.

Information on the random sequence generation and allocation concealment was reported in ten $[6,7,13,15,17,19,20,23-25]$ and 13 studies $[5,7,10,12,13,15-17,19,20,23-25]$, respectively. Thirteen RCTs [5-7,12-14,16,17,19,20,23-25] were double blind; two studies were open label [11,18] and other two $[10,15]$ had a single-blind design. Only two $[24,25]$ specifically provided information on blinding of the outcome assessors. Attrition bias was low in 11 studies $[5,6,10,11,13,16,17,19,20,23,24]$ and unclear in one [18]; five RCTs $[7,12,14,15,25]$ reported an overall high incidence of drop-out (>21\%). Reporting bias was low in all but one study [14]. Risk of funding bias was potentially high in six studies $[12,14-16,20,24]$ while three other studies specifically declared any sponsor involvement $[7,13,19]$. No other potential source of bias was apparently present in the remaining studies. 
Table 2. Risk of bias in randomized controlled trials.

\begin{tabular}{|c|c|c|c|c|c|c|c|}
\hline Study, Year (ref.) & $\begin{array}{c}\text { Random Sequence } \\
\text { Generation }\end{array}$ & $\begin{array}{l}\text { Allocation } \\
\text { Concealment }\end{array}$ & $\begin{array}{l}\text { Blinding of } \\
\text { Participants and } \\
\text { Personnel }\end{array}$ & $\begin{array}{l}\text { Blinding of } \\
\text { Outcome } \\
\text { Assessors }\end{array}$ & Incomplete Outcome Data & Selective Reporting & Other Sources of Bias \\
\hline Bliss et al., 1996 [10] & Unclear (not stated) & $\begin{array}{l}\text { Low risk ("placebo } \\
\text { and prebiotic were } \\
\text { similar in } \\
\text { appearance, taste } \\
\text { and viscosity") }\end{array}$ & $\begin{array}{l}\text { High risk } \\
\text { (single blind) }\end{array}$ & $\begin{array}{l}\text { Unclear } \\
\text { (not stated) }\end{array}$ & $\begin{array}{l}\text { Low risk (four drop-outs, } \\
20 \% \text {; per-protocol analysis } \\
\text { performed) }\end{array}$ & Low risk & None known \\
\hline Younes et al., 2006 [11] & Unclear (not stated) & $\begin{array}{c}\text { Unclear } \\
\text { (not stated) }\end{array}$ & $\begin{array}{l}\text { High risk } \\
\text { (open label) }\end{array}$ & $\begin{array}{c}\text { Unclear } \\
\text { (not stated) }\end{array}$ & Low risk (no drop-out) & Low risk & None known \\
\hline $\begin{array}{c}\text { Ranganathan et al., } 2010 \\
\text { [12] }\end{array}$ & Unclear (not stated) & $\begin{array}{l}\text { Low risk ("placebo } \\
\text { and probiotic were } \\
\text { similar in color, } \\
\text { size and } \\
\text { visual look") }\end{array}$ & $\begin{array}{c}\text { Low risk } \\
\text { (double blind) }\end{array}$ & $\begin{array}{l}\text { Unclear } \\
\text { (not stated) }\end{array}$ & $\begin{array}{l}\text { High risk ( } 16 \text { drop-outs, } \\
26 \% \text {; per-protocol } \\
\text { analysis performed) }\end{array}$ & Low risk & $\begin{array}{l}\text { High risk of funding bias } \\
\text { ("Kibow Biotech has funded } \\
\text { publication of the article") }\end{array}$ \\
\hline Guida et al., 2014 [13] & $\begin{array}{c}\text { Low risk } \\
\text { (computer-generated } \\
\text { random binary list) }\end{array}$ & $\begin{array}{l}\text { Low risk ("placebo } \\
\text { and synbiotic were } \\
\text { comparable in } \\
\text { color, texture } \\
\text { and taste") }\end{array}$ & $\begin{array}{c}\text { Low risk } \\
\text { (double blind) }\end{array}$ & $\begin{array}{l}\text { Unclear } \\
\text { (not stated) }\end{array}$ & Low risk (no drop-out) & Low risk & $\begin{array}{c}\text { Low risk of funding bias } \\
\text { ("No external funding for } \\
\text { the study") }\end{array}$ \\
\hline $\begin{array}{c}\text { Ranganathan et al., } 2014 \\
{[14]}\end{array}$ & Unclear (not stated) & $\begin{array}{c}\text { Unclear } \\
\text { (not stated) }\end{array}$ & $\begin{array}{c}\text { Low risk } \\
\text { (double blind) }\end{array}$ & $\begin{array}{l}\text { Unclear } \\
\text { (not stated) }\end{array}$ & $\begin{array}{l}\text { High risk (six drop-outs, } \\
21 \% \text {; per-protocol } \\
\text { analysis performed) }\end{array}$ & $\begin{array}{l}\text { High risk (insufficient } \\
\text { information on uremic } \\
\text { toxins and QoL) }\end{array}$ & $\begin{array}{l}\text { High risk of funding bias } \\
\text { ("Kibow Biotech financed } \\
\text { the clinical investigation; } \\
\text { part of the data was also } \\
\text { obtained in Kibow's own } \\
\text { equipped } \\
\text { research laboratories") }\end{array}$ \\
\hline Sirich et al., 2014 [15] & $\begin{array}{c}\text { Low risk } \\
\text { (permuted-block } \\
\text { randomization) }\end{array}$ & $\begin{array}{l}\text { Low risk ("fiber } \\
\text { supplements and } \\
\text { control were } \\
\text { provided as white } \\
\text { powder in } \\
\text { identical sachets") }\end{array}$ & $\begin{array}{l}\text { High risk } \\
\text { (single blind) }\end{array}$ & $\begin{array}{l}\text { Unclear } \\
\text { (not stated) }\end{array}$ & $\begin{array}{l}\text { High risk ( } 16 \text { drop-outs, } \\
28.5 \% \text {; per-protocol } \\
\text { analysis performed) }\end{array}$ & Low risk & $\begin{array}{c}\text { High risk of funding bias } \\
\text { ("T.L.S. was supported by a } \\
\text { Mitsubishi Tanabe Pharma } \\
\text { Corporation, National } \\
\text { Kidney Foundation } \\
\text { Fellowship for the Study } \\
\text { of Uremia") }\end{array}$ \\
\hline
\end{tabular}


Table 2. Cont.

\begin{tabular}{|c|c|c|c|c|c|c|c|}
\hline Study, Year (ref.) & $\begin{array}{c}\text { Random Sequence } \\
\text { Generation }\end{array}$ & $\begin{array}{l}\text { Allocation } \\
\text { Concealment }\end{array}$ & $\begin{array}{c}\text { Blinding of } \\
\text { Participants and } \\
\text { Personnel }\end{array}$ & $\begin{array}{l}\text { Blinding of } \\
\text { Outcome } \\
\text { Assessors }\end{array}$ & Incomplete Outcome Data & Selective Reporting & Other Sources of Bias \\
\hline Firouzi et al., 2015 [7] & $\begin{array}{c}\text { Low risk } \\
\text { ("computer-generated } \\
\text { random-blocks of four } \\
\text { and eight in order to } \\
\text { allow having exact } \\
\text { number of } 68 \text { in } \\
\text { each group") }\end{array}$ & $\begin{array}{c}\text { Low risk } \\
\text { (“probiotic and } \\
\text { placebo sachets } \\
\text { were identical in } \\
\text { weight, } \\
\text { appearance, } \\
\text { texture, nutritional } \\
\text { value and smell”) }\end{array}$ & $\begin{array}{c}\text { Low risk } \\
\text { (double blind) }\end{array}$ & $\begin{array}{c}\text { Unclear } \\
\text { (not stated) }\end{array}$ & $\begin{array}{l}\text { High risk ( } 35 \text { drop-outs, } \\
29 \% \text { vs. } 22 \% \text {; ITT and } \\
\text { per-protocol } \\
\text { analyses performed) }\end{array}$ & Low risk & $\begin{array}{l}\text { Low risk of funding bias } \\
\text { (“Hexbio®B-Crobes } \\
\text { Laboratory Sdn. Bhd. did } \\
\text { not interfere with the } \\
\text { decision to exploit } \\
\text { research results”) }\end{array}$ \\
\hline $\begin{array}{l}\text { Viramontes-Horner et al., } \\
2015 \text { [16] }\end{array}$ & Unclear (not stated) & $\begin{array}{l}\text { Low risk ("placebo } \\
\text { and symbiotic } \\
\text { supplement had } \\
\text { identical color, size } \\
\text { and flavor") }\end{array}$ & $\begin{array}{c}\text { Low risk } \\
\text { (double blind) }\end{array}$ & $\begin{array}{l}\text { Unclear } \\
\text { (not stated) }\end{array}$ & $\begin{array}{l}\text { Low risk (seven drop-outs, } \\
16 \% \text {; per-protocol } \\
\text { analysis performed) }\end{array}$ & Low risk & $\begin{array}{l}\text { High risk of funding bias } \\
\text { ("FMC worked for } \\
\text { Nutrimentos Inteligentes, } \\
\text { S.A. de C.V., the funders of } \\
\text { the study, providing } \\
\text { methodological and } \\
\text { statistical support") }\end{array}$ \\
\hline Wang et al., 2015 [17] & $\begin{array}{c}\text { Low risk } \\
\text { (computer-generated } \\
\text { random-number } \\
\text { table sequence) }\end{array}$ & $\begin{array}{c}\text { Low risk } \\
\text { (“allocations } \\
\text { contained in } \\
\text { opaque, } \\
\text { sequentially } \\
\text { numbered, sealed } \\
\text { envelopes") }\end{array}$ & $\begin{array}{c}\text { Low risk } \\
\text { (double blind) }\end{array}$ & $\begin{array}{l}\text { Unclear } \\
\text { (not stated) }\end{array}$ & $\begin{array}{l}\text { Low risk (eight drop-outs, } \\
17 \% \text {; per-protocol } \\
\text { analysis performed) }\end{array}$ & Low risk & None known \\
\hline Dehghani et al., 2016 [5] & Unclear (not stated) & $\begin{array}{l}\text { Low risk ("placebo } \\
\text { and synbiotic } \\
\text { produced in } \\
\text { similar color and } \\
\text { appearance; } \\
\text { patients and } \\
\text { researcher were } \\
\text { not informed of } \\
\text { the boxes' codes) }\end{array}$ & $\begin{array}{c}\text { Low risk } \\
\text { (double blind) }\end{array}$ & $\begin{array}{l}\text { Unclear } \\
\text { (not stated) }\end{array}$ & $\begin{array}{l}\text { Low risk (nine drop-outs, } \\
12 \% \text {; per-protocol } \\
\text { analysis performed) }\end{array}$ & Low risk & None known \\
\hline Pavan et al., 2016 [18] & Unclear (not stated) & $\begin{array}{c}\text { Unclear } \\
\text { (not stated) }\end{array}$ & $\begin{array}{l}\text { High risk } \\
\text { (open label) }\end{array}$ & $\begin{array}{c}\text { Unclear } \\
\text { (not stated) }\end{array}$ & Unclear (not stated) & Low risk & None known \\
\hline
\end{tabular}


Table 2. Cont

\begin{tabular}{|c|c|c|c|c|c|c|c|}
\hline Study, Year (ref.) & $\begin{array}{l}\text { Random Sequence } \\
\text { Generation }\end{array}$ & $\begin{array}{l}\text { Allocation } \\
\text { Concealment }\end{array}$ & $\begin{array}{c}\text { Blinding of } \\
\text { Participants and } \\
\text { Personnel } \\
\end{array}$ & $\begin{array}{l}\text { Blinding of } \\
\text { Outcome } \\
\text { Assessors }\end{array}$ & Incomplete Outcome Data & Selective Reporting & Other Sources of Bias \\
\hline Poesen et al., 2016 [19] & $\begin{array}{l}\text { High risk } \\
\text { ("randomization } \\
\text { performed by the } \\
\text { sealed envelope } \\
\text { system; the study } \\
\text { nurse randomly } \\
\text { opened a preformed } \\
\text { envelope containing } \\
\text { the allocated } \\
\text { treatment regimen") }\end{array}$ & $\begin{array}{c}\text { Low risk } \\
\text { ("prebiotic or } \\
\text { placebo provided } \\
\text { in identical vials } \\
\text { and boxes, labeled } \\
\text { with a numerical } \\
\text { code, unique to } \\
\text { treatment } \\
\text { allocation") }\end{array}$ & $\begin{array}{c}\text { Low risk } \\
\text { (double blind) }\end{array}$ & $\begin{array}{l}\text { Unclear } \\
\text { (not stated) }\end{array}$ & $\begin{array}{l}\text { Low risk (one drop-out; ITT } \\
\text { analysis performed) }\end{array}$ & Low risk & $\begin{array}{l}\text { Low risk of funding bias } \\
\text { ("Funders had no role in } \\
\text { study design, data } \\
\text { collection and analysis, } \\
\text { decision to publish or } \\
\text { preparation of } \\
\text { the manuscript") }\end{array}$ \\
\hline SYNERGY 2016 [20] & $\begin{array}{c}\text { Low risk ("A } \\
\text { computer-generated } \\
\text { randomization list } \\
\text { with blocks of size } 2 \\
\text { produced by an } \\
\text { external } \\
\text { statistical consultant") }\end{array}$ & $\begin{array}{l}\text { Low risk } \\
\text { (“allocation } \\
\text { concealed to } \\
\text { researchers and } \\
\text { participants; } \\
\text { supplements were } \\
\text { packed off-site } \\
\text { with a generic } \\
\text { label, supplement } \\
\text { A or B") } \\
\end{array}$ & $\begin{array}{c}\text { Low risk } \\
\text { (double blind) }\end{array}$ & $\begin{array}{c}\text { Unclear } \\
\text { (not stated) }\end{array}$ & $\begin{array}{l}\text { Low risk (six drop-outs, } \\
16 \% \text {; per-protocol } \\
\text { analysis performed) }\end{array}$ & Low risk & $\begin{array}{l}\text { High risk of funding bias } \\
\text { ("Study funded through a } \\
\text { project grant from the } \\
\text { Princess Alexandra Private } \\
\text { Practice Trust Fund (PPTF) } \\
\text { M.R. received the Princess } \\
\text { Alexandra PPTF } \\
\text { Postgraduate Scholarship") }\end{array}$ \\
\hline Guida et al., 2017 [23] & $\begin{array}{l}\text { Low risk } \\
\text { ("randomization, 2:1, } \\
\text { conducted using a } \\
\text { computer-generated } \\
\text { random binary list,") }\end{array}$ & $\begin{array}{c}\text { Low risk } \\
\text { ("synbiotic and } \\
\text { placebo powders } \\
\text { were comparable } \\
\text { in color, texture, } \\
\text { and taste") }\end{array}$ & $\begin{array}{c}\text { Low risk } \\
\text { (double blind) }\end{array}$ & $\begin{array}{c}\text { Unclear } \\
\text { (not stated) }\end{array}$ & $\begin{array}{l}\text { Low risk (two drop-outs, } \\
5.5 \% \text {; per-protocol analysis } \\
\text { performed) }\end{array}$ & Low risk & None known \\
\hline $\begin{array}{c}\text { Miraghajani et al., } 2017 \\
\text { [24] }\end{array}$ & $\begin{array}{l}\text { Low risk (allocation } \\
\text { by randomly } \\
\text { permuted blocks) }\end{array}$ & $\begin{array}{c}\text { Low risk } \\
\text { (“concealed } \\
\text { envelopes with } \\
\text { consecutive } \\
\text { numbers were } \\
\text { locked in a drawer } \\
\text { and withdrawn in } \\
\text { numerical order") }\end{array}$ & $\begin{array}{c}\text { Low risk } \\
\text { (double blind) }\end{array}$ & $\begin{array}{l}\text { Low risk } \\
\text { ("outcome's } \\
\text { assessors and } \\
\text { analyses' } \\
\text { performers were } \\
\text { masked to } \\
\text { group assignment") }\end{array}$ & $\begin{array}{l}\text { Low risk (eight drop-outs, } \\
16.6 \% \text {; per-protocol } \\
\text { analysis performed) }\end{array}$ & Low risk & $\begin{array}{l}\text { High risk of funding bias } \\
\text { ("Financial support } \\
\text { provided by the Security } \\
\text { Research Center, Isfahan } \\
\text { University of Medical } \\
\text { Sciences, Isfahan, Iran") }\end{array}$ \\
\hline
\end{tabular}


Table 2. Cont.

\begin{tabular}{|c|c|c|c|c|c|c|c|}
\hline Study, Year (ref.) & $\begin{array}{l}\text { Random Sequence } \\
\text { Generation }\end{array}$ & $\begin{array}{l}\text { Allocation } \\
\text { Concealment }\end{array}$ & $\begin{array}{c}\text { Blinding of } \\
\text { Participants and } \\
\text { Personnel }\end{array}$ & $\begin{array}{l}\text { Blinding of } \\
\text { Outcome } \\
\text { Assessors }\end{array}$ & Incomplete Outcome Data & Selective Reporting & Other Sources of Bias \\
\hline Soleimani et al., 2017 [6] & $\begin{array}{c}\text { Low risk } \\
\text { ("randomization } \\
\text { conducted using } \\
\text { computer-generated } \\
\text { random numbers") }\end{array}$ & $\begin{array}{l}\text { Unclear } \\
\text { (not stated) }\end{array}$ & $\begin{array}{c}\text { Low risk } \\
\text { (double blind) }\end{array}$ & $\begin{array}{l}\text { Unclear } \\
\text { (not stated) }\end{array}$ & $\begin{array}{l}\text { Low risk (five drop-outs, } \\
8 \% \text {; ITT analysis performed) }\end{array}$ & Low risk & None known \\
\hline Borges et al., 2018 [25] & $\begin{array}{l}\text { High risk (manually } \\
\text { generated } \\
\text { simple randomization) }\end{array}$ & $\begin{array}{c}\text { Low risk } \\
\text { ("participant and } \\
\text { researcher were } \\
\text { blinded to the } \\
\text { contents of bottles } \\
\text { containing placebo } \\
\text { and } \\
\text { probiotic capsules") }\end{array}$ & $\begin{array}{c}\text { Low risk } \\
\text { (double blind) }\end{array}$ & $\begin{array}{c}\text { Low risk } \\
\text { ("outcome } \\
\text { measurements } \\
\text { performed in a } \\
\text { blinded manner") }\end{array}$ & $\begin{array}{l}\text { High risk (13 drop-outs, } \\
28 \% \text {; per-protocol } \\
\text { analysis performed) }\end{array}$ & Low risk & None known \\
\hline
\end{tabular}




\subsection{Outcome Data}

Data on renal function, defined as change in creatinine clearance/eGFR, was available from nine RCTs [5-7,11,13,17,18,20,23] while eleven studies [5-7,10-12,16-18,20,25] provided data on end of treatment serum creatinine. Non-fatal CV events were recorded by one study [5] while no data were available on mortality.

End of treatment proteinuria and/or albuminuria was provided by one study [20]. Among inflammation indexes, six RCTs [6,12,14-16,25] provided data on C-reactive protein, four studies [16,17,20,25] analyzed IL-6 levels and three studies [16,17,20] TNF- $\alpha$. Changes in other chemokines, such as progranulin, IL-1 $\beta$, IL-5, IL-10 and IL-17, were reported by single trials $[17,20,24]$. Fifteen studies [5-7,10-17,19,20,23,25] reported changes in azotemia and other uremic toxins. Finally, four trials $[12,14,15,20]$ provided information on quality of life and two trials $[6,16]$ reported patient nutritional status as a subjective global assessment (SGA) score.

\subsection{Effects of Biotic Supplements on Primary Outcomes}

\subsubsection{Renal Function (GFR/Creatinine Clearance)}

In a study of $39 \mathrm{PD}$ patients [17], residual renal function $\left(\mathrm{mL} / \mathrm{min} / 1.73 \mathrm{~m}^{2}\right)$ was apparently higher after six months of probiotic treatment (1.59; IQR 0.85-2.93) with respect to placebo (1.24; IQR 0.50-2.74) but no statistical comparison between groups was made.

In another study of stage 3-5 CKD patients not on dialysis [18], GFR declined more rapidly among controls than in the active group $(-11.6 \pm 8.6$ vs. $-3.4 \pm 4.6$ per year; $p<0.001)$.

Conversely, another trial [13] did not report significant differences in end of treatment GFR between mild-to-moderate CKD patients receiving synbiotics or placebo.

This latter observation was in agreement with findings from a pooled meta-analysis of six RCTs (345 individuals) [5-7,11,20,23] showing no apparent effect of biotic supplementation on renal function as compared with control (MD $0.34 \mathrm{~mL} / \mathrm{min} / 1.73 \mathrm{~m}^{2}$; 95\% CI -0.19, 0.86; Figure 2). This analysis had no heterogeneity $\left(\mathrm{Chi}^{2}=3.13, p=0.68, \mathrm{I}^{2}=0 \%\right)$ and no evidence of publication bias (Supplementary Figure S1). Study stratification by CKD stage of participants, type of biotic supplementation administered or study design (blind vs open label) did not change overall findings.

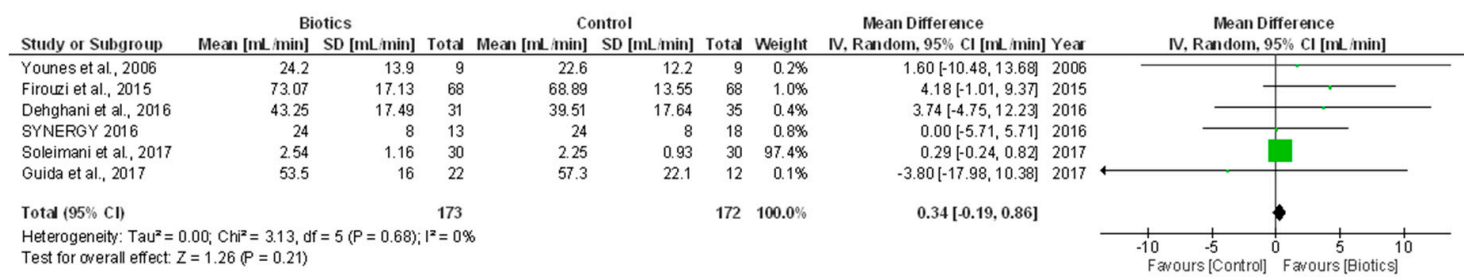

Figure 2. Effects of biotics supplementation vs. control treatment on eGFR/creatinine clearance; eGFR-estimated glomerular filtration rate.

\subsubsection{Serum Creatinine}

In single-study data, no statistically significant differences in end-of-treatment serum creatinine were found amongst HD [16] or PD [17] patients receiving biotic supplements or placebo. These observations were in line with a cumulative meta-analysis of nine RCTs (492 individuals) [5-7,10-12,18,20,25] showing no significant change in serum creatinine after treatment with biotics versus control (MD $-0.13 \mathrm{mg} / \mathrm{dL} ; 95 \% \mathrm{CI}-0.32,0.07$; Figure 3 ). This analysis had mild heterogeneity $\left(\mathrm{Chi}^{2}=13.30, p=0.10 ; I^{2}=40 \%\right)$ that was totally nullified $\left(I^{2}=0 \%\right)$ after excluding two studies enrolling HD patients [6,25]. Visual inspection of the funnel plot and the Egger's regression test indicate no presence of publication bias (Supplementary Figure S1). 


\begin{tabular}{|c|c|c|c|c|c|c|c|c|c|c|}
\hline Study or Subgroup & \multicolumn{3}{|c|}{$\begin{array}{c}\text { Biotics } \\
\text { Mean }\end{array}$} & \multicolumn{3}{|c|}{$\begin{array}{c}\text { Control } \\
\text { Mean }\end{array}$} & \multicolumn{2}{|c|}{ Mean Difference } & \multicolumn{2}{|c|}{$\begin{array}{c}\text { Mean Difference } \\
\text { IV, Random, } 95 \% \mathrm{CI}[\mathrm{mg} / \mathrm{dL}]\end{array}$} \\
\hline Eliss et al., 1996 & 4.5 & 3.2 & 16 & 4.7 & 3.6 & 16 & $0.7 \%$ & $-0.20[-2.56,2.16] 1996$ & & \\
\hline Younes et al., 2006 & 3.85 & 1.66 & 9 & 4.6 & 1.63 & 9 & $1.5 \%$ & $-0.75[-2.27,0.77] 2006$ & & \\
\hline Ranganathan et al. 2010 & 4.42 & 2.61 & 46 & 4.71 & 3.89 & 46 & $1.9 \%$ & $-0.29[-1.64,1.06] 2010$ & & \\
\hline Firouzi et al., 2015 & 0.82 & 0.22 & 68 & 0.85 & 0.22 & 68 & $37.0 \%$ & $-0.03[-0.10,0.04] 2015$ & & \\
\hline Dehghani et al., 2016 & 1.9 & 0.7 & 31 & 2.18 & 1.14 & 35 & $12.4 \%$ & $-0.28[-0.73,0.17] 2016$ & & - \\
\hline SYNERGY 2016 & 2.63 & 0.85 & 13 & 2.65 & 0.84 & 18 & $8.1 \%$ & $-0.02[-0.62,0.58] 2016$ & & \\
\hline Pavan et al., 2016 & 4.45 & 0.3 & 12 & 4.3 & 0.31 & 12 & $24.0 \%$ & $0.15[-0.09,0.39] 2016$ & & - \\
\hline Soleimani et al., 2017 & 7.2 & 2.6 & 30 & 7.7 & 2.9 & 30 & $1.8 \%$ & $-0.50[-1.89,0.89] 2017$ & & \\
\hline Borges et al., 2018 & 9.6 & 0.7 & 16 & 10.3 & 0.6 & 17 & $12.6 \%$ & $-0.70[-1.15,-0.25] 2018$ & $\longrightarrow$ & \\
\hline Total $(95 \% \mathrm{Cl})$ & & & 241 & & & 251 & $100.0 \%$ & $-0.13[-0.32,0.07]$ & & \\
\hline $\begin{array}{l}\text { Heterogeneity: } \operatorname{Tau}^{2}=0.0 \\
\text { Test for overall effect: } Z=\end{array}$ & $\begin{array}{l}\text { Chi }=13.30, d t \\
.30(P=0.20)\end{array}$ & $=8(P=0.10)$ & $F^{2}=40$ & & & & & & $\begin{array}{ll} & 1 \\
-2 & -1 \\
\text { Favours (Biotics) }\end{array}$ & \begin{tabular}{|lll} 
& 1 & 1 \\
0 & 1 & 2 \\
Favours [controll]
\end{tabular} \\
\hline
\end{tabular}

Figure 3. Effects of biotics supplementation vs. control treatment on serum creatinine.

\subsubsection{Cardiovascular Morbidity}

One study [5] reported one non-fatal cerebrovascular accident in a patient receiving synbiotic supplements, as compared to placebo.

\subsection{Effects of Biotic Supplements on Secondary Outcomes}

\subsubsection{Proteinuria/Albuminuria}

In one study of hypertensive CKD patients [20], 16 weeks of synbiotic treatment significantly increased albuminuria by $38 \mathrm{mg} / 24 \mathrm{~h}(95 \% \mathrm{CI}, 1$ to $295 \mathrm{mg} / 24 \mathrm{~h})$, although it did not affect total urinary protein excretion.

\subsubsection{Inflammation Indexes}

In PD patients [17], six months of treatment with probiotics significantly reduced serum levels of the pro-inflammatory cytokines TNF- $\alpha$, IL- 5 and IL- 6 and increased those of the anti-inflammatory cytokine IL-10. Another trial [24] showed that consumption of probiotics soy milk resulted in a significant reduction $(p=0.01)$ in levels of the inflammatory adipokine progranulin as compared with placebo. Conversely, in the SYNERGY trial [20], there were no significant changes in serum concentrations of IL-1 $\beta$, IL-6, IL-10 and TNF- $\alpha$ after synbiotic supplementation, with respect to placebo. No concrete benefits on inflammation were reported by the other two studies [14,16]. In line with these latter findings, a pooled meta-analysis of three RCTs (133 individuals) $[6,15,25]$ reported no significant change in C-reactive protein after biotic supplementation versus placebo (MD $0.75 \mathrm{mg} / \mathrm{dL} ; 95 \% \mathrm{CI}$ $-1.54,3.03$; Figure 4). A high level of heterogeneity was present $\left(\mathrm{Chi}^{2}=7.45, p=0.02, I^{2}=73 \%\right)$ that could not be further investigated given the paucity of studies included.

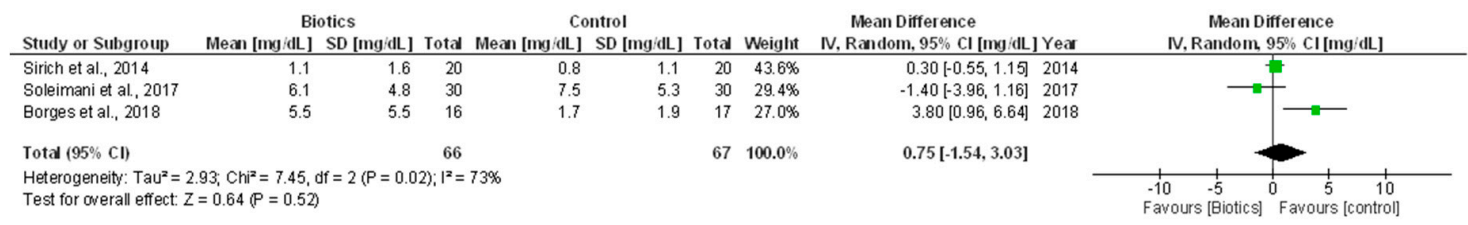

Figure 4. Effects of biotics supplementation vs. control treatment on C-reactive protein.

\subsubsection{Urea and Other Uremic Toxins}

No differences in urea levels were reported in studies of PD [17] and pre-dialysis ESKD individuals [19] receiving a probiotic formulation as compared to placebo.

In a pooled meta-analysis including nine RCTs (512 individuals) [5-7,10-12,15,16,25], we found no tangible effect of biotic supplements on urea as compared with control (SMD $-0.02 ; 95 \% \mathrm{CI}-0.25$, 0.20 ; Figure 5). This analysis had a mild level of heterogeneity $\left(C h i^{2}=11.88, p=0.16 ; I^{2}=33 \%\right)$ that was nullified after excluding four RCTs $[6,15,16,25]$ performed on HD patients and no apparent publication bias (Supplementary Figure S1). 
In two single studies enrolling moderate-to-severe CKD patients [13,20], synbiotic administration significantly reduced serum/plasma p-cresol concentration which, conversely, remained stable in the placebo arm. Similar findings were reported in another study of kidney transplant recipients [23] but were not confirmed by three other RCTs enrolling HD [15,25] as well as stage 4-5 CKD (not on dialysis) patients [19].

In one study of $40 \mathrm{HD}$ patients [15], prebiotic treatment reduced plasma levels of free indoxyl sulfate, as compared to control group; conversely, in another study of 33 HD individuals [25], a significant increase in indoxyl sulfate was reported after 12 weeks of probiotic supplementation, with respect to placebo. Finally, no significant variations in this uremic toxin were reported by two more studies performed on moderate-to-severe CKD patients [19,20].

In one study of HD patients [14] a decreasing, although not statistically significant, trend was observed in total indoxyl glucuronide concentrations $(-0.11 \mathrm{mg} \%, p=0.058)$ after probiotic administration vs. placebo.

One study [19] reported no significant effects of prebiotics on the levels of p-cresyl glucuronide and phenyl-acetyl-glutamine (PAG) but a small, albeit significant reduction of serum trimethylamine N-oxide (TMAO) $(p=0.04)$.

Finally, probiotic supplementation failed to reduce indole-3 acetic-acid (IAA) after 12 weeks of treatment in one trial enrolling ESKD patients on chronic HD [25].

\begin{tabular}{|c|c|c|c|c|c|c|c|c|c|c|c|c|c|}
\hline \multirow[b]{2}{*}{ Study or Subgroup } & \multicolumn{3}{|c|}{ Biotics } & \multicolumn{3}{|c|}{ Control } & \multicolumn{3}{|c|}{ Std. Mean Difference } & \multirow{2}{*}{\multicolumn{4}{|c|}{$\begin{array}{l}\text { Std. Mean Difference } \\
\text { IV, Random, } 95 \% \mathrm{Cl}\end{array}$}} \\
\hline & Mean & SD & Total & Mean & SD & Total & Weight & IV, Random, $95 \% \mathrm{Cl}$ & Year & & & & \\
\hline Eliss et al., 1996 & 44 & 20 & 16 & 52 & 32 & 16 & $8.0 \%$ & $-0.29[-0.99,0.40]$ & 1996 & & & & \\
\hline Younes et al., 2006 & 20.2 & 8.2 & 9 & 26.1 & 8.7 & 9 & $4.7 \%$ & $-0.66[-1.62,0.29]$ & 2006 & & & & \\
\hline Ranganathan et al. 2010 & 23.82 & 12.01 & 46 & 25.89 & 15.14 & 46 & $16.2 \%$ & $-0.15[-0.56,0.26]$ & 2010 & & & & \\
\hline Sirich et al., 2014 & 56 & 14 & 20 & 60 & 19 & 20 & $9.5 \%$ & $-0.23[-0.86,0.39]$ & 2014 & & & & \\
\hline Viramontes-Horner et al., 2015 & 148.6 & 41.6 & 20 & 131.5 & 43.8 & 15 & $8.3 \%$ & $0.39[-0.28,1.07]$ & 2015 & & & & \\
\hline Firouzi et al., 2015 & 4.04 & 1.04 & 68 & 4.24 & 1.14 & 68 & $19.7 \%$ & $-0.18[-0.52,0.15]$ & 2015 & & & - & \\
\hline Dehghani et al., 2016 & 36.14 & 20.52 & 31 & 39.62 & 27.56 & 35 & $13.3 \%$ & $-0.14[-0.62,0.34]$ & 2016 & & & & \\
\hline Soleimani et al., 2017 & 63.9 & 26 & 30 & 52.3 & 12.7 & 30 & $12.2 \%$ & $0.56[0.04,1.08]$ & 2017 & & & & \\
\hline Borges et al., 2018 & 172.6 & 45 & 16 & 155.9 & 38.6 & 17 & $8.1 \%$ & $0.39[-0.30,1.08]$ & 2018 & & & & \\
\hline Total $(95 \% \mathrm{Cl})$ & & & 256 & & & 256 & $100.0 \%$ & $-0.02[-0.25,0.20]$ & & & & & \\
\hline $\begin{array}{l}\text { Heterogeneity: } \mathrm{Tau}^{2}=0.04 ; \mathrm{Chi}^{2} \\
\text { Test for overall effect: } Z=0.20 \text { (f }\end{array}$ & $\begin{array}{l}=11.88, \\
=0.84)\end{array}$ & $d f=8(f$ & $P=0.1$ & 6); $1^{2}=$ & & & & & & -2 & $\begin{array}{c}-1 \\
\text { Favours [Biotics] }\end{array}$ & Favours [c & $\begin{array}{l}1 \\
\text { control] }\end{array}$ \\
\hline
\end{tabular}

Figure 5. Effects of biotics supplementation vs. control treatment on urea levels.

\subsubsection{Quality of Life (QoL)}

In one RCT [12], the majority of subjects receiving probiotics experienced a considerable improvement in overall QoL $(86 \%, \mathrm{p}<0.05)$, with respect to those allocated to placebo.

Conversely, no difference in patient-reported health (KDQOL-36) between the active and control group was observed by three other RCTs $[14,15,20]$.

\subsubsection{Nutritional Status}

One study [16] found no difference in nutritional status after treatment with synbiotic supplements or placebo (19/20 vs. 11/15 well-nourished individuals; $p>0.05)$. In another study [6], however, probiotic supplementation produced a significant reduction in SGA score $(-0.7 \pm 2.2$ vs. $+0.7 \pm 1.8$; $p=0.01)$ as compared with placebo.

\section{Discussion}

To the best of our knowledge, this systematic review and meta-analysis is the largest and most updated evaluation of the effects of biotic supplements in individuals affected by chronic kidney disease of various severities. Unfortunately, despite information from an adequate number of RCTs and participants (17 studies, 701 individuals), the question as to whether biotics should be advocated in this population setting for improving outcomes remains generally unanswered due to several limitations in the available evidence. 
CKD triggers a substantial derangement in the gut microbiota, both in terms of quantity and quality of colonizing bacteria species. This dysbiotic condition is partly consequent to some iatrogenic habits, such as frequent use of antibiotics [26], decreased consumption of dietary fiber [27] or chronic oral iron intake [28]. However, uremia may also alter the normal balance between symbiotic and pathogen bacteria per se [29]. In fact, excess urea due to reduced renal function is secreted into the gastrointestinal tract, where bacterial ureases generate large amounts of ammonia that eventually hamper the growth of commensal microbe species [30]. In renal patients, intestinal dysbiosis also enhances protein fermentation leading to an increased generation of other gut-derived uremic toxins. Similar to urea, such toxins accumulate in the circulation due to a reduced clearance capacity by the failing kidney or, in chronic ESKD dialysis patients, due to the scarce capacity of hemodialysis biomembranes to remove them efficiently. Not surprisingly, serum concentrations of indoxyl sulfate and p-cresyl sulfate have been found to be inversely correlated with residual renal function in CKD individuals [31] and higher levels of indoxyl sulfate and p-cresol have been observed among chronic HD patients with colons, as compared to those without [32]. Although several animal and small uncontrolled clinical studies indicate that biotics might be effective in reducing amines, indoles and cresoles by restoring an optimal gut bacterial milieu [23,33-36], the vast majority of RCTs included in the present review failed to demonstrate efficacy of these supplements to decrease various uremic toxins. However, information in these studies was mostly available in a format that was not suitable to be pooled in cumulative analyses, hence limiting the possibility to draw overall conclusions in a definite manner.

Uremic toxins are also recognized to accelerate renal disease progression and to increase cardiovascular risk. In uremic rats, administration of indoxyl sulfate induces glomerulosclerosis, renal fibrosis and promotes a significant decline in renal function [37]. In various clinical studies, indoxyl sulfate and p-cresyl sulfate were independent predictors of CKD [38-40] and were associated with adverse cardiovascular outcomes, particularly in hemodialysis populations [41-43].

Another main aim of our review was to ascertain whether modulation of gut microbiota by biotic supplements could improve renal and cardiovascular outcomes of CKD individuals, as suggested by preliminary available evidence [44]. Unfortunately, we found only a single trial reporting on CV morbidity (cerebrovascular accidents) [5] with just one event recorded, while no study provided information on cardiac events or mortality.

Pooled analyses focusing on end-of-treatment eGFR/creatinine clearance or serum creatinine did not show evidence of efficacy of biotics in improving renal function as compared with the control.

However, despite such analyses, summarized data from a reasonable number of studies had null heterogeneity and no evidence of publication bias; the generalizability of these (negative) findings remains questionable due to the short to very short treatment period and the small, underpowered sample size of the study populations. Finally, no study provided information on other, more standardized indicators of CKD progression, such as doubling of serum creatinine events, need for dialysis or renal transplantation or eGFR slope over time.

Sustained inflammation is a major hallmark of chronic kidney disease, becoming more prominent as renal failure progresses to end-stage kidney disease, requiring chronic dialysis.

Such an inflammatory state is associated with adverse outcomes, including anemia and erythropoietin hyporesponsiveness, malnutrition, impaired quality of life and, above all, exceedingly high cardiovascular disease with increased mortality and hospitalization.

It is now acknowledged that dysbiosis in the intestinal microflora may contribute to systemic inflammation in CKD. This is mostly due to an increased translocation of endotoxins and other uremic toxins into the circulation, with consequent hyper-activation of monocytes, neutrophils and granulocytes leading to an altered balance between pro- and anti-inflammatory cytokines [45]. In patients undergoing chronic peritoneal- or hemo-dialysis, positive correlations have been found between lipopolysaccharides from gut bacteria and C-reactive protein levels $[46,47]$ and subclinical endotoxemia has recently been acknowledged as a relevant cause for inflammation in patients with 
CKD $[48,49]$. Biotic administration may also improve the pro-inflammatory status of CKD patients [50]. Our systematic literature search retrieved a considerable number of RCTs $(n=13)$ testing the effects of biotic supplements on inflammatory markers in renal patients. Yet, there was poor agreement among single study findings and the myriad different pro- or anti-inflammatory cytokines analyzed from various studies hampered the possibility of drawing definite conclusions on a cumulative basis. Conversely, a pooled meta-analysis of the only three RCTs with suitable data on C-reactive protein showed no apparent impact of biotics over control on this inflammatory index; such a negative finding, however, could hardly be generalized in a reliable manner given the paucity of evidence available.

Our review has points of strength and limitations that deserve mentioning. Strengths include a comprehensive systematic approach to the existing literature, study selection, data extraction and quality assessment that have all been conducted according to current methodological standards. Furthermore, we intentionally focused only on randomized controlled trials as a way to minimize selection bias and potential confounding factors, and we considered an ample list of outcomes without restrictions on study duration and type of intervention in order to maximize information gathering.

Limitations mostly rely on the small sample size, the heterogeneity in terms of CKD stage, type and duration of treatment and, as briefly alluded to before, the short follow-up of studies included. Study duration was in most cases of few weeks / months and, hence, not adequate to capture statistically significant differences in parameters of renal function or in the occurrence of cardiovascular events. As a result, most studies actually focused on surrogate, rather than hard endpoints and data on some other clinically relevant outcomes, such as quality of life or nutritional status, were sparse or lacking. Heterogeneity in time and methods of measurement of some end-points may represent another key issue. For instance, serum creatinine and urea levels in chronic dialysis patients are notoriously influenced by the type and efficacy of the dialysis technique itself and by the time point (e.g., preor post-dialysis session or during a long or short interval between two sessions) in which they were measured. As most studies did not provide this information in full, the generalizability of findings to the whole dialysis population remains problematic.

Finally, the relatively low number of studies finally included in pooled analyses prevented the possibility to perform more complex investigations, such as additional subgroup or meta-regression analyses, in order to identify all potential treatment-effect modifiers or sub-categories of patients that could possibly take benefit from these supplements as compared to others.

In conclusion, data from currently available RCTs do not provide a clear rationale for suggesting a widespread use of biotic supplements for improving outcomes in renal patients. Future, well-designed and adequately powered trials focusing on hard rather than surrogate outcomes (e.g., mortality/morbidity; CKD progression) are hence advocated for clarifying this issue.

Supplementary Materials: The following are available online at http:/ /www.mdpi.com/2072-6643/10/9/1224/s1.

Author Contributions: Conceptualization, D.B. and G.C.; Methodology, D.B., A.P. and G.D.; Formal Analysis, D.B., A.P. and G.D.; Writing-Original Draft Preparation, D.B. and G.C.; Writing-Review and Editing, D.B., G.C., A.P. and G.D. Anna Pisano participated in manuscript writing, collaborated on study selection, data collection/analysis and interpretation, helped in drafting the paper. Davide Bolignano and Giuseppe Coppolino collaborated on research idea, study design and co-wrote the manuscript. Davide Bolignano participated in data analysis and interpretation, prepared the first draft of the manuscript. Graziella D'Arrigo collaborated on study selection, data collection and helped in statistical analysis and data interpretation.

Funding: All the authors have declared no funding.

Conflicts of Interest: The authors declare no conflict of interest with respect to the present.

\section{References}

1. Daliri, E.B.; Tango, C.N.; Lee, B.H.; Oh, D.H. Human microbiome restoration and safety. Int. J. Med. Microbiol. 2018, 308, 487-497. [CrossRef] [PubMed]

2. Yang, T.; Richards, E.M.; Pepine, C.J.; Raizada, M.K. The gut microbiota and the brain-gut-kidney axis in hypertension and chronic kidney disease. Nat. Rev. Nephrol. 2018, 14, 442-456. [CrossRef] [PubMed] 
3. Kanbay, M.; Onal, E.M.; Afsar, B.; Dagel, T.; Yerlikaya, A.; Covic, A.; Vaziri, N.D. The crosstalk of gut microbiota and chronic kidney disease: Role of inflammation, proteinuria, hypertension, and diabetes mellitus. Int. Urol. Nephrol. 2018, 50, 1453-1466. [CrossRef] [PubMed]

4. Briskey, D.; Tucker, P.; Johnson, D.W.; Coombes, J.S. The role of the gastrointestinal tract and microbiota on uremic toxins and chronic kidney disease development. Clin. Exp. Nephrol. 2017, 21, 7-15. [CrossRef] [PubMed]

5. Dehghani, H.; Heidari, F.; Mozaffari-Khosravi, H.; Nouri-Majelan, N.; Dehghani, A. Synbiotic supplementations for azotemia in patients with chronic kidney disease: A randomized controlled trial. Iran. J. Kidney Dis. 2016, 10, 351-357. [PubMed]

6. Soleimani, A.; Zarrati Mojarrad, M.; Bahmani, F.; Taghizadeh, M.; Ramezani, M.; Tajabadi-Ebrahimi, M.; Jafari, P.; Esmaillzadeh, A.; Asemi, Z. Probiotic supplementation in diabetic hemodialysis patients has beneficial metabolic effects. Kidney Int. 2017, 91, 435-442. [CrossRef] [PubMed]

7. Firouzi, S.; Mohd-Yusof, B.N.; Majid, H.A.; Ismail, A.; Kamaruddin, N.A. Effect of microbial cell preparation on renal profile and liver function among type 2 diabetics: A randomized controlled trial. BMC Complement. Altern. Med. 2015, 15, 433. [CrossRef] [PubMed]

8. Moher, D.; Liberati, A.; Tetzlaff, J.; Altman, D.G. Preferred reporting items for systematic reviews and meta-analyses: The prisma statement. PLoS Med. 2009, 6, e1000097. [CrossRef] [PubMed]

9. National Kidney Foundation. K/doqi clinical practice guidelines for chronic kidney disease: Evaluation, classification, and stratification. Am. J. Kidney Dis. 2002, 39, S1-S266.

10. Bliss, D.Z.; Stein, T.P.; Schleifer, C.R.; Settle, R.G. Supplementation with gum arabic fiber increases fecal nitrogen excretion and lowers serum urea nitrogen concentration in chronic renal failure patients consuming a low-protein diet. Am. J. Clin. Nutr. 1996, 63, 392-398. [CrossRef] [PubMed]

11. Younes, H.; Egret, N.; Hadj-Abdelkader, M.; Remesy, C.; Demigne, C.; Gueret, C.; Deteix, P.; Alphonse, J.C. Fermentable carbohydrate supplementation alters nitrogen excretion in chronic renal failure. J. Ren. Nutr. 2006, 16, 67-74. [CrossRef] [PubMed]

12. Ranganathan, N.; Ranganathan, P.; Friedman, E.; Joseph, A.; Delano, B.; Goldfarb, D.; Tam, P.; Rao, A.; Anteyi, E.; Musso, C. Pilot study of probiotic dietary supplementation for promoting healthy kidney function in patients with chronic kidney disease. Adv. Ther. 2010, 27, 634-647. [CrossRef] [PubMed]

13. Guida, B.; Germano, R.; Trio, R.; Russo, D.; Memoli, B.; Grumetto, L.; Barbato, F.; Cataldi, M. Effect of short-term synbiotic treatment on plasma p-cresol levels in patients with chronic renal failure: A randomized clinical trial. Nutr. Metab. Cardiovasc. Dis. 2014, 24, 1043-1049. [CrossRef] [PubMed]

14. Natarajan, R.; Pechenyak, B.; Vyas, U.; Ranganathan, P.; Weinberg, A.; Liang, P.; Mallappallil, M.C.; Norin, A.J.; Friedman, E.A.; Saggi, S.J. Randomized controlled trial of strain-specific probiotic formulation (renadyl) in dialysis patients. Biomed. Res. Int. 2014, 2014, 568571. [CrossRef] [PubMed]

15. Sirich, T.L.; Plummer, N.S.; Gardner, C.D.; Hostetter, T.H.; Meyer, T.W. Effect of increasing dietary fiber on plasma levels of colon-derived solutes in hemodialysis patients. Clin. J. Am. Soc. Nephrol. 2014, 9, 1603-1610. [CrossRef] [PubMed]

16. Viramontes-Horner, D.; Marquez-Sandoval, F.; Martin-del-Campo, F.; Vizmanos-Lamotte, B.; Sandoval-Rodriguez, A.; Armendariz-Borunda, J.; Garcia-Bejarano, H.; Renoirte-Lopez, K.; Garcia-Garcia, G. Effect of a symbiotic gel (lactobacillus acidophilus + bifidobacterium lactis + inulin) on presence and severity of gastrointestinal symptoms in hemodialysis patients. J. Ren. Nutr. 2015, 25, 284-291. [CrossRef] [PubMed]

17. Wang, I.; Wu, Y.; Yang, Y.; Ting, I.; Lin, C.; Yen, T.; Chen, J.; Wang, C.; Huang, C.; Lin, H. The effect of probiotics on serum levels of cytokine and endotoxin in peritoneal dialysis patients: A randomised, double-blind, placebo-controlled trial. Benef. Microbes 2015, 6, 423-430. [CrossRef] [PubMed]

18. Pavan, M. Influence of prebiotic and probiotic supplementation on the progression of chronic kidney disease. Minerva Urol. Nefrol. 2016, 68, 222-226. [PubMed]

19. Poesen, R.; Evenepoel, P.; de Loor, H.; Delcour, J.A.; Courtin, C.M.; Kuypers, D.; Augustijns, P.; Verbeke, K.; Meijers, B. The influence of prebiotic arabinoxylan oligosaccharides on microbiota derived uremic retention solutes in patients with chronic kidney disease: A randomized controlled trial. PLoS One 2016, 11, e0153893. [CrossRef] [PubMed]

20. Rossi, M.; Johnson, D.W.; Morrison, M.; Pascoe, E.M.; Coombes, J.S.; Forbes, J.M.; Szeto, C.C.; McWhinney, B.C.; Ungerer, J.P.; Campbell, K.L. Synbiotics easing renal failure by improving gut microbiology (synergy): A randomized trial. Clin. J. Am. Soc. Nephrol. 2016, 11, 223-231. [CrossRef] [PubMed] 
21. Rossi, M.; Johnson, D.; Morrison, M.; Pascoe, E.; Coombes, J.; Forbes, J.; Szeto, C.-C.; McWhinney, B.; Ungerer, J.; Campbell, K. Pre \& probiotic therapy in chronic kidney disease: A randomised controlled trial. Rev. Esp. Nutr. Hum. Diet. 2016, 20, 449.

22. Rossi, M.; Johnson, D.W.; Morrison, M.; Pascoe, E.; Coombes, J.S.; Forbes, J.M.; McWhinney, B.C.; Ungerer, J.P.; Dimeski, G.; Campbell, K.L. Synbiotics easing renal failure by improving gut microbiology (synergy): A protocol of placebo-controlled randomised cross-over trial. BMC Nephrol. 2014, 15, 106. [CrossRef] [PubMed]

23. B, G. Effect of a short-course treatment with synbiotics on plasma p-cresol concentration in kidney transplant recipients. J. Am. Coll. Nutr. 2017, 36, 586-591.

24. Miraghajani, M.; Zaghian, N.; Dehkohneh, A.; Mirlohi, M.; Ghiasvand, R. Probiotic soy milk consumption and renal function among type 2 diabetic patients with nephropathy: A randomized controlled clinical trial. Probiotics Antimicrob. Proteins 2017, 1-9. [CrossRef] [PubMed]

25. Borges, N.A.; Carmo, F.L.; Stockler-Pinto, M.B.; de Brito, J.S.; Dolenga, C.J.; Ferreira, D.C.; Nakao, L.S.; Rosado, A.; Fouque, D.; Mafra, D. Probiotic supplementation in chronic kidney disease: A double-blind, randomized, placebo-controlled trial. J. Ren. Nutr. 2018, 28, 28-36. [CrossRef] [PubMed]

26. Jakobsson, H.E.; Jernberg, C.; Andersson, A.F.; Sjolund-Karlsson, M.; Jansson, J.K.; Engstrand, L. Short-term antibiotic treatment has differing long-term impacts on the human throat and gut microbiome. PLoS ONE 2010, 5, e9836. [CrossRef] [PubMed]

27. Kalantar-Zadeh, K.; Kopple, J.D.; Deepak, S.; Block, D.; Block, G. Food intake characteristics of hemodialysis patients as obtained by food frequency questionnaire. J. Ren. Nutr. 2002, 12, 17-31. [CrossRef] [PubMed]

28. Goraya, N.; Wesson, D.E. Dietary management of chronic kidney disease: Protein restriction and beyond. Curr. Opin. Nephrol. Hypertens. 2012, 21, 635-640. [CrossRef] [PubMed]

29. Kang, J.Y. The gastrointestinal tract in uremia. Dig. Dis. Sci. 1993, 38, 257-268. [CrossRef] [PubMed]

30. Noel, S.; Martina-Lingua, M.N.; Bandapalle, S.; Pluznick, J.; Hamad, A.R.; Peterson, D.A.; Rabb, H. Intestinal microbiota-kidney cross talk in acute kidney injury and chronic kidney disease. Nephron. Clin. Pract. 2014, 127, 139-143. [CrossRef] [PubMed]

31. Lin, C.J.; Chen, H.H.; Pan, C.F.; Chuang, C.K.; Wang, T.J.; Sun, F.J.; Wu, C.J. P-cresylsulfate and indoxyl sulfate level at different stages of chronic kidney disease. J. Clin. Lab. Anal. 2011, 25, 191-197. [CrossRef] [PubMed]

32. Aronov, P.A.; Luo, F.J.; Plummer, N.S.; Quan, Z.; Holmes, S.; Hostetter, T.H.; Meyer, T.W. Colonic contribution to uremic solutes. J. Am. Soc. Nephrol. 2011, 22, 1769-1776. [CrossRef] [PubMed]

33. Mafra, D.; Lobo, J.C.; Barros, A.F.; Koppe, L.; Vaziri, N.D.; Fouque, D. Role of altered intestinal microbiota in systemic inflammation and cardiovascular disease in chronic kidney disease. Future Microbiol. 2014, 9, 399-410. [CrossRef] [PubMed]

34. Meijers, B.K.; De Preter, V.; Verbeke, K.; Vanrenterghem, Y.; Evenepoel, P. P-cresyl sulfate serum concentrations in haemodialysis patients are reduced by the prebiotic oligofructose-enriched inulin. Nephrol. Dial. Transplant. 2010, 25, 219-224. [CrossRef] [PubMed]

35. Miranda Alatriste, P.V.; Urbina Arronte, R.; Gomez Espinosa, C.O.; Espinosa Cuevas Mde, L. Effect of probiotics on human blood urea levels in patients with chronic renal failure. Nutr. Hosp. 2014, 29, 582-590. [PubMed]

36. Nakabayashi, I.; Nakamura, M.; Kawakami, K.; Ohta, T.; Kato, I.; Uchida, K.; Yoshida, M. Effects of synbiotic treatment on serum level of p-cresol in haemodialysis patients: A preliminary study. Nephrol. Dial. Transplant 2011, 26, 1094-1098. [CrossRef] [PubMed]

37. Miyazaki, T.; Ise, M.; Hirata, M.; Endo, K.; Ito, Y.; Seo, H.; Niwa, T. Indoxyl sulfate stimulates renal synthesis of transforming growth factor-beta 1 and progression of renal failure. Kidney Int. Suppl. 1997, 63, S211-S214. [PubMed]

38. Wu, I.W.; Hsu, K.H.; Lee, C.C.; Sun, C.Y.; Hsu, H.J.; Tsai, C.J.; Tzen, C.Y.; Wang, Y.C.; Lin, C.Y.; $\mathrm{Wu}$, M.S. P-cresyl sulphate and indoxyl sulphate predict progression of chronic kidney disease. Nephrol. Dial. Transplant. 2011, 26, 938-947. [CrossRef] [PubMed]

39. Liabeuf, S.; Barreto, D.V.; Barreto, F.C.; Meert, N.; Glorieux, G.; Schepers, E.; Temmar, M.; Choukroun, G.; Vanholder, R.; Massy, Z.A.; et al. Free p-cresylsulphate is a predictor of mortality in patients at different stages of chronic kidney disease. Nephrol. Dial. Transplant. 2010, 25, 1183-1191. [CrossRef] [PubMed] 
40. Lin, C.J.; Liu, H.L.; Pan, C.F.; Chuang, C.K.; Jayakumar, T.; Wang, T.J.; Chen, H.H.; Wu, C.J. Indoxyl sulfate predicts cardiovascular disease and renal function deterioration in advanced chronic kidney disease. Arch. Med. Res. 2012, 43, 451-456. [CrossRef] [PubMed]

41. Wu, I.W.; Hsu, K.H.; Hsu, H.J.; Lee, C.C.; Sun, C.Y.; Tsai, C.J.; Wu, M.S. Serum free p-cresyl sulfate levels predict cardiovascular and all-cause mortality in elderly hemodialysis patients-a prospective cohort study. Nephrol. Dial. Transplant. 2012, 27, 1169-1175. [CrossRef] [PubMed]

42. Barreto, F.C.; Barreto, D.V.; Liabeuf, S.; Meert, N.; Glorieux, G.; Temmar, M.; Choukroun, G.; Vanholder, R.; Massy, Z.A.; European Uremic Toxin Work, G. Serum indoxyl sulfate is associated with vascular disease and mortality in chronic kidney disease patients. Clin. J. Am. Soc. Nephrol. 2009, 4, 1551-1558. [CrossRef] [PubMed]

43. Bammens, B.; Evenepoel, P.; Keuleers, H.; Verbeke, K.; Vanrenterghem, Y. Free serum concentrations of the protein-bound retention solute p-cresol predict mortality in hemodialysis patients. Kidney Int. 2006, 69, 1081-1087. [CrossRef] [PubMed]

44. Krishnamurthy, V.M.; Wei, G.; Baird, B.C.; Murtaugh, M.; Chonchol, M.B.; Raphael, K.L.; Greene, T.; Beddhu, S. High dietary fiber intake is associated with decreased inflammation and all-cause mortality in patients with chronic kidney disease. Kidney Int. 2012, 81, 300-306. [CrossRef] [PubMed]

45. Vanholder, R.; Glorieux, G. The intestine and the kidneys: A bad marriage can be hazardous. Clin. Kidney J. 2015, 8, 168-179. [CrossRef] [PubMed]

46. Terawaki, H.; Yokoyama, K.; Yamada, Y.; Maruyama, Y.; Iida, R.; Hanaoka, K.; Yamamoto, H.; Obata, T.; Hosoya, T. Low-grade endotoxemia contributes to chronic inflammation in hemodialysis patients: Examination with a novel lipopolysaccharide detection method. Ther. Apher. Dial. 2010, 14, 477-482. [CrossRef] [PubMed]

47. Hauser, A.B.; Stinghen, A.E.; Goncalves, S.M.; Bucharles, S.; Pecoits-Filho, R. A gut feeling on endotoxemia: Causes and consequences in chronic kidney disease. Nephron. Clin. Pract. 2011, 118, c165-c172; discussion c172. [CrossRef] [PubMed]

48. McIntyre, C.W.; Harrison, L.E.; Eldehni, M.T.; Jefferies, H.J.; Szeto, C.C.; John, S.G.; Sigrist, M.K.; Burton, J.O.; Hothi, D.; Korsheed, S.; et al. Circulating endotoxemia: A novel factor in systemic inflammation and cardiovascular disease in chronic kidney disease. Clin. J. Am. Soc. Nephrol. 2011, 6, 133-141. [CrossRef] [PubMed]

49. Feroze, U.; Kalantar-Zadeh, K.; Sterling, K.A.; Molnar, M.Z.; Noori, N.; Benner, D.; Shah, V.; Dwivedi, R.; Becker, K.; Kovesdy, C.P.; et al. Examining associations of circulating endotoxin with nutritional status, inflammation, and mortality in hemodialysis patients. J. Ren. Nutr. 2012, 22, 317-326. [CrossRef] [PubMed]

50. Alvarenga Borges, N.; Elias Farage, N.; Faria Barros, A.; Carvalho Ferreira, D.; Fouque, D.; Mafra, D. Synbiotic supplementation promotes improvement of chronic diarrhea of unknown etiology in patient with chronic kidney disease and provides better outcomes in dialysis. Nutr. Hosp. 2016, 33, 182-184. [CrossRef] [PubMed]

(C) 2018 by the authors. Licensee MDPI, Basel, Switzerland. This article is an open access article distributed under the terms and conditions of the Creative Commons Attribution (CC BY) license (http:// creativecommons.org/licenses/by/4.0/). 